\title{
Alpha-Synuclein-Nanoparticle Interactions: Understanding, Controlling and Exploiting Conformational Plasticity
}

\author{
Mariapina D’Onofrio (D), Francesca Munari and Michael Assfalg *(D) \\ Department of Biotechnology, University of Verona, 37134 Verona, Italy; mariapina.donofrio@univr.it (M.D.); \\ francesca.munari@univr.it (F.M.) \\ * Correspondence: michael.assfalg@univr.it; Tel.: +39-045-8027939 \\ Academic Editor: Pil Seok Chae \\ Received: 25 September 2020; Accepted: 27 November 2020; Published: 29 November 2020

\begin{abstract}
Alpha-synuclein $(\alpha S)$ is an extensively studied protein due to its involvement in a group of neurodegenerative disorders, including Parkinson's disease, and its documented ability to undergo aberrant self-aggregation resulting in the formation of amyloid-like fibrils. In dilute solution, the protein is intrinsically disordered but can adopt multiple alternative conformations under given conditions, such as upon adsorption to nanoscale surfaces. The study of $\alpha$ S-nanoparticle interactions allows us to better understand the behavior of the protein and provides the basis for developing systems capable of mitigating the formation of toxic aggregates as well as for designing hybrid nanomaterials with novel functionalities for applications in various research areas. In this review, we summarize current progress on $\alpha$ S-nanoparticle interactions with an emphasis on the conformational plasticity of the biomolecule.
\end{abstract}

Keywords: alpha-synuclein; amyloid fibrils; conformational flexibility; protein adsorption; protein aggregation; nano-bio interface; nanocomposite; nanoparticles; supramolecular assembly

\section{Introduction}

Alpha-synuclein $(\alpha S)$ is a paradigmatic and one of the most extensively investigated intrinsically disordered proteins (IDPs) [1,2]. It is an abundant neuronal protein which localizes predominantly to presynaptic terminals and binds to small synaptic vesicles [3]. The biological function of the protein remains enigmatic, although increasing evidence supports its participation in neurotransmission and synaptic plasticity, including roles in synaptic vesicle recycling and neurotransmitter synthesis and release [4-6]. $\alpha S$ has also been reported to interact with and affect a variety of proteins [7]. Soon after its discovery, the protein became infamous for being strongly linked, genetically and pathologically, to Parkinson's disease (PD) and other neurodegenerative diseases characterized by abnormal accumulation of insoluble $\alpha$ S deposits [8-10].

Encoded by the SNCA gene, $\alpha \mathrm{S}$ is a $14-\mathrm{kDa}$ polypeptide which can be broadly divided into three domains: an amphiphilic N-terminal region (residues 1-60) that contains four imperfect eleven-residue amino acid repeats, a hydrophobic, amyloidogenic domain (residues 61-95, referred to as non-amyloid- $\beta$ component, NAC, domain) with three additional repeats, and an acidic $C$ terminus (residues 96-140) $[9,11]$. In dilute solution, $\alpha \mathrm{S}$ is unstructured and best described as a dynamic ensemble of interconverting conformations [12-14]. Mounting evidence indicates that native oligomers exist in cells, which exhibit greater aggregation resistance than the disordered monomeric species [15-18]. Environmental changes, binding events and other stimuli may promote the transition from the soluble monomeric and small oligomeric states to higher-level oligomers, fibrils (highly ordered supramolecular nanostructures) and amorphous aggregates $[12,15,19,20]$. The high protein solubility 
and the possibility to trigger conformational changes in vitro upon exposure to specific environments and stimuli, have made $\alpha \mathrm{S}$ a popular model for structural and aggregation studies of IDPs [1,21].

In the context of amyloidogenic, unfolded peptides and proteins like $\alpha$, nanoparticles (NPs) have attracted interest as artificial receptors or chaperones against the formation of toxic aggregates [22]. NP surfaces, acting as a scaffold for protein adsorption, could provide the means to redirect aggregation pathways, sequester/correct misfolded structures, retard or accelerate aggregation and disaggregate assemblies. NPs are versatile platforms, they can be prepared in a wide range of sizes and with diverse surface chemistries. In principle, by careful design of the NPs it should be possible to control their interactions with biological components and develop artificial receptors capable of biomolecular recognition [23-28]. Among the vast array of potential applications that rely on optimized target recognition, NPs represent a promising alternative to conventional small drugs for targeting protein-protein interactions associated with pathological conditions [24] and indeed have emerged as a new class of therapeutics [29].

The nanometer scale of their size makes NPs able to interact with cellular systems and biomolecular networks and to reach targets of biomedical interest [30]. Upon exposure to biological media, NPs tend to be covered by a layer of biomolecules, generally consisting of an internal, long-lived layer (termed hard corona) and a more loosely associated, external layer (termed soft corona) [30]. The protein corona mediates the interactions with the living systems and determines the physiological responses [30,31]. Unintended protein adsorption onto NPs may perturb the protein's activity as a consequence of binding-induced changes in structure, stability or the exposure of recognition sites [32]. It is thus essential to characterize both the structural and dynamic organization of the corona and the modes of binding of distinct biomolecules to the NP surface [33].

The ability of ad-hoc prepared NPs to target and associate to specific proteins can be extended to the development of novel hybrid materials composed of proteins and NPs, which feature unique attributes not attainable with the separate components [34]. Protein-NP bioconjugation is an attractive method to fabricate functional materials enabling applications in sensing, delivery and other nanotechnological areas [34]. Protein molecules can be used to coat the NPs and protect them from the medium, to join multiple NPs in order to form higher order supramolecular assemblies, they can be introduced into hollow structures of the NPs or be surrounded by them [35]. The variety of conformational states of certain disordered and self-aggregating proteins may be exploited to tune the properties of the hybrid material to different purposes.

A number of groups have strived to elucidate the modes of binding of $\alpha \mathrm{S}$ to simple NPs made by different core materials, including silica, gold and lipids, which exhibit biocompatibility and can be easily functionalized [36-38]. A variety of experimental and computational techniques were applied to gain information at the molecular and sub-molecular level on the organization of $\alpha \mathrm{S}$ molecules within a hard corona, on the NP-induced structural transitions, the determinants of binding and the dynamic exchange processes at the nano-bio interface. The possibility to perturb the aggregation behavior of $\alpha \mathrm{S}$ by use of NPs has attracted considerable interest $[39,40]$. Research efforts were largely focused on the observation of aggregation kinetics curves of $\alpha \mathrm{S}$ in the presence or absence of NPs, providing insight into the aggregation process at the macroscopic level [41]. A mechanistic description of the effects of NPs on the aggregation kinetics has lagged behind, however few reports have provided preliminary insight into the microscopic events and structural conversions taking place during $\alpha \mathrm{S}$ aggregation [42-44]. Interestingly, certain NPs were shown to interact with and disassemble preformed amyloid fibrils [40]. Tailored interactions between $\alpha$ S and NPs were further explored to develop reactive agents and nanobiocomposites featuring novel attributes for application in nanotherapeutics, nanooptics, nanoelectronics and other areas [45,46]. A large number of studies have been carried out to explore how NPs bind to and influence the aggregation propensity of diverse amyloidogenic proteins and peptides other than $\alpha \mathrm{S}$ [22], however $\alpha \mathrm{S}$ appears to have attracted greater attention than other IDPs for developing composite nanomaterials, presumably due to its unique favorable properties, such as molecular size, solubility, stability and ease of production. 
The objective of this review is to summarize progress made in the study of $\alpha \mathrm{S}$ interactions with NPs, with an emphasis on the conformational plasticity of the protein and its self-assembling propensity. The review is divided into three sections discussing: (1) fundamental aspects and molecular determinants of $\alpha \mathrm{S}$ adsorption onto NP surfaces; (2) efforts aimed at controlling $\alpha \mathrm{S}$ self-aggregation, formation of toxic assemblies and disaggregation of insoluble fibrils; (3) achievements towards the fabrication of $\alpha S$-based hybrid materials presenting novel functionalities. We aim to provide the basis for better understanding the conformational properties of $\alpha \mathrm{S}$ at the interface with NPs and illustrate how this knowledge may support our ability to control $\alpha \mathrm{S}$ structural transitions and to design functional nanocomposites. Among the large variety of known NPs, we decided to focus our survey on the simplest type, namely particles of near-spherical shape. The selected case studies comprise both inorganic and organic materials as well as lipid nanovesicles. While the former types are attractive tools for exploratory purposes and applications, the latter are included for their great relevance as biomembrane mimics to probe $\alpha \mathrm{S}$ conformational versatility and membrane surface-induced structural transitions.

\section{Adsorption of Monomeric Alpha-Synuclein onto Nanoparticles}

\subsection{Silica Nanoparticles}

The distinct physicochemical environment of the hard and the soft corona is expected to influence differently the conformational preferences of protein molecules. Recent work by Grandori and coworkers focused on the characterization of the conformations of $\alpha \mathrm{S}$ and other proteins in the hard corona of silica NPs (SNPs) [37]. To prepare corona-coated SNPs, SNPs ( 50 nm) were incubated with excess $\alpha S$ and then subjected to centrifugation and washing cycles. Based on transmission electron microscopy (TEM) analysis, the $\alpha \mathrm{S}$ corona was found to be formed by a monolayer of tightly bound, collapsed molecules. Circular dichroism (CD) and Fourier-transform infrared (FTIR) spectra suggested the formation of helical segments on adsorption of $\alpha S$ to SNPs, however the effect was rather limited, indicating that the disordered state remained prevalent. Despite the limitations of the single experimental techniques in the analysis of protein-NP hybrids, such as possible scattering effects affecting CD experiments, the work demonstrated that a combination of them could provide useful structural insights into adsorbed protein layers.

To complement the knowledge acquired on the hard corona, a subsequent study was aimed at the characterization of $\alpha$ S molecules in dynamic exchange with the surface of SNPs [38]. Tira et al. used nuclear magnetic resonance (NMR) spectroscopy to gain insight into the adsorption mechanism at single-residue resolution. The direct observation of NMR signals from NP-bound proteins is generally unfeasible due to excessive line-broadening caused by the slow rotational tumbling of the hybrid species, however perturbations may be detected as intensity losses or exchange-averaged observables $[47,48]$. Indeed, heteronuclear single quantum correlation (HSQC) spectra and relaxation rate measurements performed on samples containing $\alpha \mathrm{S}$ and SNPs revealed that the amphipathic amino-terminal domain was the primary contact with the NP surface, while the carboxy-terminal domain retained significant mobility (Figure 1A,B). An oxidized form of $\alpha$, containing four methionine sulfoxides, associated with oxidative stress, was found to exhibit similar binding properties as the unmodified species, indicating that the increased hydrophilicity did not influence the binding to SNPs. Interestingly, $\alpha S$ interacted with the surface of SNPs also in the molecularly crowded environment of blood serum with similar orientation as in simple buffer (Figure 1C). Additional competition binding experiments, supported by sodium dodecyl sulfate-polyacrylamide gel electrophoresis (SDS-PAGE) analysis, showed that $\alpha S$ was able to displace serum albumin and other proteins from the surface of NPs, while the highly basic four-repeat domain of Tau, an amyloidogenic IDP, displayed stronger affinity to SNPs, compared to $\alpha$ S. Thus, $\alpha$ S adsorption was described as a dynamic process wherein molecular exchange on the surface determines the composition and organization of the protein corona. 

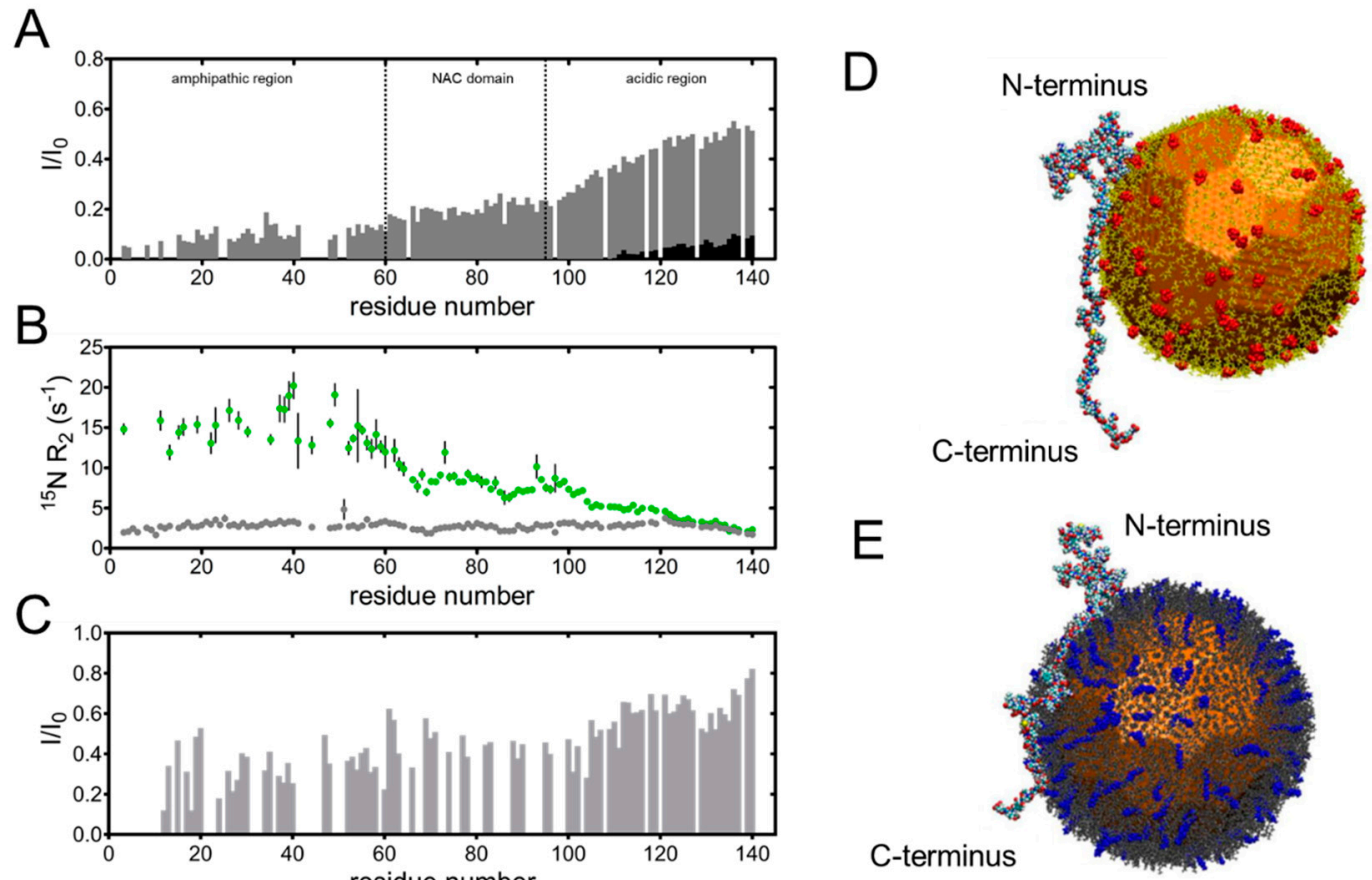

Figure 1. Orientation of $\alpha \mathrm{S}$ molecules on the surface of nanoparticles. (A-C) Site-resolved nuclear magnetic resonance (NMR) interaction profiles revealing amino acid residues of $\alpha \mathrm{S}$ involved in binding to silica nanoparticles (SNPs) on the basis of intensity attenuations or increased nuclear spin relaxation rates. (A) Relative signal intensities obtained from heteronuclear single quantum correlation (HSQC) spectra measured on ${ }^{15} \mathrm{~N}$-enriched $\alpha \mathrm{S}$ dissolved in buffer solution, in the absence of SNPs $\left(I_{0}\right)$ or in their presence (I), at two different concentrations (gray and black bars). (B) ${ }^{15} \mathrm{~N}$ transverse relaxation rate values measured in the absence (gray dots) and presence of SNPs (green dots). (C) Relative HSQC signal intensities measured on ${ }^{15} \mathrm{~N}$-enriched $\alpha \mathrm{S}$ in human blood serum containing (I) and not containing $\left(I_{0}\right)$ SNPs. Adapted from ref. [38], Copyright 2020, with permission from Elsevier. (D,E) Rendering of simulated interaction of $\alpha S$ with AuNPs showing the reversed orientation of the protein depending on the capping ligand. (D) Interaction with citrate-capped AuNPs. (E) Interaction with MTAB-capped AuNPs. Citrate and MTAB ligands are charged (highlighted in red and blue, respectively). Adapted with permission from Lin et al. J. Phys. Chem. C Nanomater. Interfaces. 2015, 119(36), 21035-21043. Copyright 2015 American Chemical Society.

The capability of nuclear magnetic resonance (NMR) spectroscopy to provide atomic-resolution information on protein-NP interactions and the qualitative observation that the binding of IDPs to certain NPs is related to the polypeptide sequence, stimulated Brüschweiler and coworkers to attempt a quantitative analysis of residue-specific NMR data [49]. The authors developed an interaction model based on a quantitative NP affinity scale determined from measurements on single amino acid types. In conditions of rapid exchange between free and surface-bound states, the difference in residue-specific ${ }^{15} \mathrm{~N}$-spin transverse relaxation rate constants, ${ }^{15} \mathrm{~N}-R_{2}$, observed in the presence and absence of NPs, termed $\Delta R_{2}$, provides a direct measure of the interaction strength between the NP and residues in the polypeptide chain. After a number of refinements, the authors came up with a binding model capable to accurately predict residue-specific binding affinities of $\alpha \mathrm{S}$ and other IDPs to SNPs [50,51]. This work provided mechanistic insight into the binding of $\alpha S$ and SNPs, explaining the observed interaction profile in terms of the non-uniform distribution of charged and neutral amino acids as well as in terms of global and local cooperativity effects.

Overall, the binding of $\alpha \mathrm{S}$ to SNPs appears as a simple reversible two-state binding mechanism mediated in large part by the lysine-rich N-terminal domain, which experiences attractive electrostatic interactions with the negatively charged, deprotonated silanol groups at the SNP surface. However, 
this simplified picture does not explain all observations, such as the apparently distinct involvement of the C-terminal domain at different protein/NP ratios and the formation of a slowly desorbing hard corona [38]. Furthermore, the role of intermolecular interactions in the structural organization of the protein corona have remained elusive. Diverse techniques have served to provide detailed descriptions of the organization of folded protein molecules bound to NPs [52-54], however similar results were not obtained for $\alpha S$, likely due to the greater difficulty of obtaining clear data for an unstructured polypeptide. All of these aspects deserve attention in future studies.

\subsection{Gold Nanoparticles}

The study of the adsorption of proteins to AuNPs has invariably involved the use of capped or functionalized AuNPs. In an early work, Murphy and coworkers investigated the interaction of $\alpha S$ with citrate-capped $20 \mathrm{~nm}$ and $90 \mathrm{~nm}$ AuNPs [55]. The authors used dynamic light scattering (DLS) to monitor changes in the mean hydrodynamic diameter after mixing the protein with the NPs. They observed the formation of a relatively thick, strongly bound adlayer (hard corona) and a less thick, labile soft corona. An overall apparent binding constant of $(2.0 \pm 0.4) \times 10^{7} \mathrm{M}^{-1}$ was estimated from the DLS data using $20 \mathrm{~nm}$ AuNPs and a similar result was obtained from the analysis of plasmon band maxima in the UV-vis spectra. Fluorescence quenching was exploited to separately quantify the binding constants for the hard and the soft corona, yielding affinity constant values in the order of $10^{7}$ $\mathrm{M}^{-1}$ and $10^{-3} \mathrm{M}^{-1}$, respectively. The latter value suggested that the binding of the soft corona was thermodynamically unfavorable and kinetically driven. The authors further attempted a structural analysis of NP-bound protein by CD using a stacked double-cuvette method but realized that high absorbance by the metallic core could compromise the quality of the obtained results. Therefore, they resorted to use enzymatic digestion followed by mass spectrometry (MS) analysis to gain insight into the structure of $\alpha S$ in the hard corona. A comparison of trypsin digestion patterns of free $\alpha S$ with bound $\alpha S$ on $20 \mathrm{~nm}$ citrate-capped AuNPs suggested that the protein maintained its native unstructured state when bound on AuNPs, with the N-terminal section strongly adsorbed onto the NP surface.

As opposed to citrate-capped AuNPs, which expose a negatively charged surface, poly (allylamine hydrochloride) (PAH) coated AuNPs display a positively charged surface. Murphy's group used a similar methodology as that used with citrate AuNP to explore the structure of $\alpha \mathrm{S}$ bound to PAH AuNPs [36]. The protein was found to adsorb as multilayers when present at low protein/NP ratios and eventually formed agglomerates at higher ratios. The latter condition was attendant with an increase in $\beta$-sheet structure and decrease in $\alpha$-helical content, possibly explaining the tendency to form agglomerates. Apparently, the mode of adsorption could elicit the seeding of a global conformational change of $\alpha S$ in the sample. Based on trypsin digestion data, the protein molecules were found to adopt random orientation in the multilayered corona.

Solution NMR spectroscopy was used in a subsequent study to obtain definitive insight into the orientation of $\alpha S$ on both anionic and cationic AuNPs [56]. For cationic particles, in spite of using PAH, AuNPs were capped with (16-mercaptohexadecyl) trimethylammonium bromide (MTAB), a ligand that did not promote protein aggregation and therefore allowed better interpretation of the NMR data. As expected, portions of the protein that bound to NPs exhibited larger linewidths and attenuated signals. A comparison of the residue-by-residue intensity profiles collected with the anionic and cationic NPs clearly showed the reverse orientation of the protein, with the prevalently basic N-terminus acting as the anchor to citrate-capped AuNPs and the acidic C-terminus being prevalently bound to MTAB AuNPs. Besides identifying the sections in direct contact with the NPs' surfaces, the NMR data also revealed that the unanchored portions experienced restricted motion due to their tethered condition. In both cases, the protein remained disordered upon binding to the NPs. Molecular dynamics (MD) simulations supported the observed reversal of protein binding orientation (Figure 1D,E) and additionally indicated that the central hydrophobic segment, the NAC domain, 
was attracted to both types of AuNPs. These results demonstrated the possibility to obtain molecular control of protein display on engineered NPs.

\subsection{Lipid Nanovesicles}

In cells, $\alpha S$ partitions between disordered or partly ordered cytosolic forms and phospholipid-bound states [57-59]. The association of $\alpha S$ with phospholipid membranes was linked to a role of the protein in the regulation of reserve pools of synaptic vesicles and dopamine homeostasis $[6,60]$. Such crucial function has spurred the investigation of $\alpha \mathrm{S}$ binding to lipid nanovesicles as membrane mimics. The N-terminal 11-mer repeat sequence of $\alpha S$, resembling the sequence motifs found in apolipoprotein A-I, suggested that it could form amphipathic helical lipid-binding domains [61]. Indeed, several in vitro studies have established that $\alpha S$ undergoes a coil-to-helix transition when binding to vesicles made by acidic phospholipids or anionic detergents [61-63].

In studies of $\alpha$ S-lipid interactions, a large variety of lipid/detergent vesicles of different composition and size have been used and several distinct experimental conditions were tested, which may in part account for the fact that results were sometimes seemingly contradictory $[2,64]$. The increase in helical content on binding of $\alpha \mathrm{S}$ to anionic phospholipid vesicles was initially observed by CD spectroscopy and the interaction was proposed to be mediated by four N-terminal helices (region 1-60) [61]. In a subsequent study, Eliezer and coworkers used small ( $\sim \mathrm{nm})$ SDS detergent micelles as membrane mimics in place of larger phospholipid vesicles to facilitate observation of the lipid-bound state by NMR spectroscopy [12]. They found that binding of $\alpha$-synuclein to SDS micelles elicited formation of an extended $\alpha$-helix encompassing residues $1-100$, while the $C$-terminal portion of the protein remained unassociated. Later investigations, based on NMR and partial tryptic digestion, identified a short break within the extended helical region [63,65]. Furthermore, spin probe-induced broadening of NMR signals, ${ }^{15} \mathrm{~N}$ relaxation measurements and fluorescence spectroscopy data indicated the presence of two N-terminal helices, positioned on the surface of the SDS micelle and separated by a flexible stretch [66]. The region of residues 61-95 was found to adopt a helical conformation but it was proposed to be partially embedded in the micelle [66]. Finally, a high resolution structural determination established that micelle-bound $\alpha$ S forms two curved $\alpha$-helices within the $\mathrm{N}$-terminal domain, connected by an ordered, extended linker in an anti-parallel arrangement, followed by another short extended region and a largely disordered tail (residues 98-140) [67].

SDS micelles have provided an invaluable system to study structural properties of lipid-bound $\alpha S$, however both the chemical composition and the size do not entirely recapitulate the features of the $\sim 50 \mathrm{~nm}$ presynaptic phospholipid vesicles. Thus, several studies have been conducted using either small or large unilamellar vesicles (SUVs or LUVs). A structural model of SUV-bound $\alpha \mathrm{S}$ was obtained by applying simulated annealing MD restrained by the immersion depths and long-range distances obtained from continuous-wave and pulsed electron paramagnetic resonance (EPR) data [68] (Figure 2). The bound form was described as an extended helix (ca. 90 amino acids long) with a curved arrangement that follows the curvature of the vesicle surface and allows lysine residues to interact with phosphate groups, acidic residues to approach the choline groups and hydrophobic residues to associate with the lipidic moieties. Further experimental evidence, based on single molecule Förster resonance energy transfer and on the use of $100 \mathrm{~nm}$ LUVs, supported the extended helix model [69], however other authors concluded that the broken-helix arrangement best described the SUV-bound protein state [70]. Later studies provided evidence for coexisting populations of broken and extended helices, in part reconciling the divergent models [71,72]. It was found that relative protein/lipid concentrations and vesicle size could modulate the preference of $\alpha S$ for distinct helical arrangements. A multiplicity of coexisting binding modes were further proposed by Bax and coworkers, featuring slow exchange kinetics and involvement of N-terminal segments of differing length [73]. 

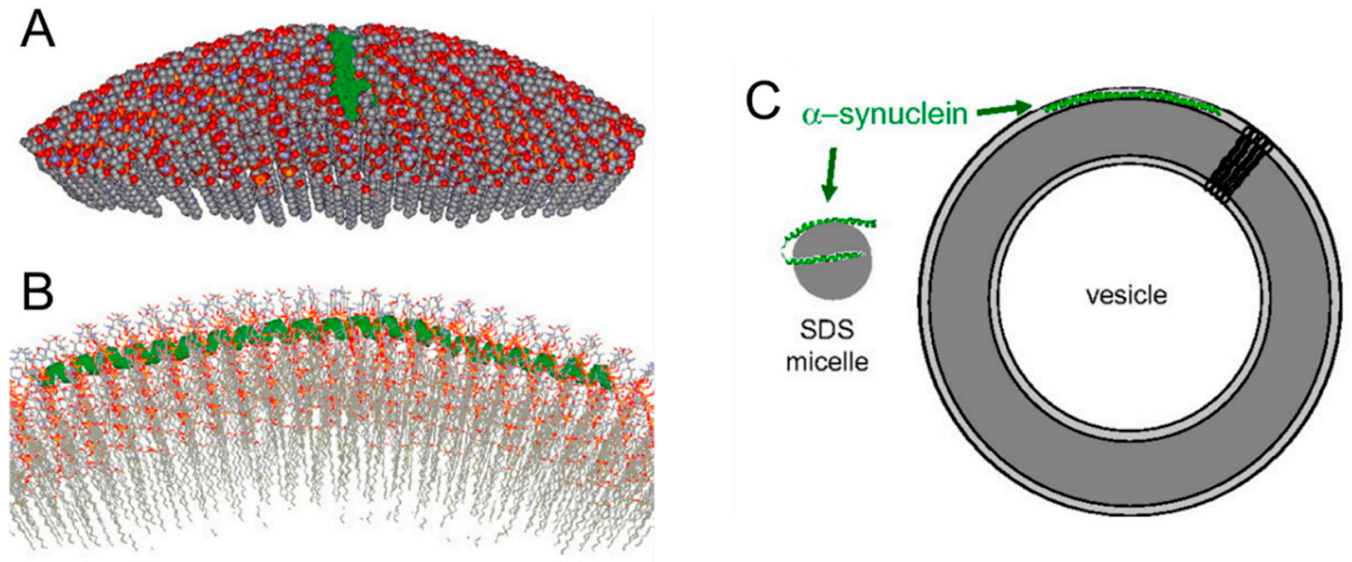

Figure 2. Interaction of $\alpha$ S with curved lipid surfaces. (A) Space-filled model of $\alpha$-synuclein (shown in green) binding to the surface of a lipid vesicle $300 \mathrm{~A}$ in diameter; $\approx 25 \%$ of the outer leaflet of the vesicle is shown. The vesicle was fitted around one of the structures derived from the experimentally restrained simulated annealing-molecular dynamics (SAMD) calculations. (B) A closer cross-sectional view of the $\alpha \mathrm{S}$ interaction with the lipid surface, with rotation through $90^{\circ}$ from the image in A. The protein (green) follows the curved surface of the vesicle, with the helical axis positioned just below the level of the phosphate groups of the lipids. This position of the protein emerged from the SAMD calculations and reflects the immersion depths obtained from the continuous-wave electron paramagnetic resonance (EPR) data. (C) Cartoon representations of the structures of $\alpha$-synuclein on micelles and small unilamellar vesicles (SUVs). The small and highly curved micelles cannot accommodate the extended helical structure present on the membrane. Adapted with permission from Jao et al., Proc. Natl. Acad. Sci. USA, 2008, 105 (50) 19666-19671. Copyright 2008 National Academy of Sciences.

Despite the complexity of lipid vesicle binding, consensus was reached about the preferential interaction of $\alpha S$ with anionic phospholipids, although non-electrostatic interactions with neutral and zwitterionic lipids were also observed. A systematic study performed with phospholipid bilayer nanodiscs, an alternative model of lipid membranes exhibiting planar surfaces, confirmed the electrostatic model and showed that the binding mode was dependent on the relative abundance of anionic lipids versus neutral molecules [74]. Additionally, the degree of saturation and the length of the acyl chains were found to influence the binding of $\alpha S[75,76]$. More specifically, molecular properties that determine the lipid phase state and membrane fluidity critically influence $\alpha S$ adsorption [74]. Interestingly, $\alpha \mathrm{S}$ and anionic phospholipids may also form nanometer-sized lipoprotein particles, reminiscent of high-density lipoproteins, in which $\alpha \mathrm{S}$ adopts a helical secondary structure [77]. Thus, the specific lipid environment has a profound impact on the partitioning and conformational transitions of $\alpha$, suggesting the possibility to tune molecular properties and regulate biomolecular and nano-bio interactions by careful design of the lipid-based nanomaterials.

\subsection{Mixed-Type and Other Nanoparticles}

The widely documented attraction of synuclein to lipid layers has inspired the development of lipid-based composite particles, other than simple vesicles. For example, Lee and coworkers used osmotic shock to coat monodisperse SNPs (60 nm diameter) with a lipid membrane, thereby obtaining spherical NP-supported lipid bilayers (SSLBs) [78]. Specifically, SNPs were amine-functionalized and the lipid coating was made by a mixture of the anionic lipid DOPA (1,2-dioleoyl-sn-glycero-3-phosphate) and the zwitterionic lipid DOPC (1,2-dioleoyl-sn-glycero-3-phosphocholine). SSLBs offer important advantages over SUVs/LUVs as they display larger X-ray scattering cross section of the silica core relative to membranes, enabling small-angle X-ray scattering (SAXS) and state-of-the-art X-ray photon correlation spectroscopy (XPCS), thereby expanding the repertoire of experimental techniques available 
to probe colloidal structure and dynamics of $\alpha$ S-bound vesicles. The authors reported that $\alpha \mathrm{S}$ disrupted vesicle-vesicle interactions, with implications for synaptic membrane fusion and the ultrastructure and dynamics of synaptic vesicle pools.

The coating of inorganic NPs with lipid layers was also recently pursued by other groups [79]. The surface of AuNPs of varying size was capped with an inner layer of dodecanethiol and an outer layer of SDS. Thus, the organic bilayer was formed on a rigid scaffold and was resistant to deformation by $\alpha S$, as opposed to lipid vesicles which are known to undergo structural remodeling upon interaction with the protein. By removing the effect of NP deformation, the obtained mimics allowed investigating the effects of NP curvature on protein binding behavior. SDS-AuNP_-bound $\alpha$ S displayed increased solvent accessibility in the NAC region, suggesting that the adsorbed protein could possess higher aggregation propensity than unbound $\alpha \mathrm{S}$.

In the study of potential applications of NPs as protein aggregation modulators, Hajipour and coworkers focused on the interaction between $\alpha \mathrm{S}$ and graphene sheets and superparamagnetic iron oxide NPs (SPIONs) with different surface properties and sizes [44]. Graphene sheets were prepared as small (150-250 nm), medium (450-650 nm) and large (800-1200 nm) sheets with polyglycerolsulfate, polyglycerol and polyglycerolamine coverages, displaying surface charges of $-30 \mathrm{mV}, 0$ and +30 $\mathrm{mV}$, respectively. The investigated SPIONs were 20, 50 and $100 \mathrm{~nm}$ large and displayed various functionalities ( $\mathrm{COOH}, \mathrm{NH}_{2}, \mathrm{PEG}-300$ and chitosan). Atomistic MD simulations indicated that the interaction of $\alpha \mathrm{S}$ with charged nano-objects was initially driven by electrostatic attraction, with a later involvement of hydrophobic residues and non-polar contacts dominating the interaction. Additionally, hydrogen bonds were formed, particularly in the case of amine-functionalized graphene. Differences in $\alpha S$ binding behavior to graphene and SPIONs were attributed to the distinct shape and corresponding surface curvature of the two materials. The affinity to neutral nano-objects was lower compared to charged ones. The various binding contributions resulted in distinct orientations of $\alpha S$ on the surface of different particles, supporting the view that distinct nanomaterials could differently affect $\alpha \mathrm{S}$ self-assembly at the nano-bio interface.

Given the application of human serum albumin (HSA) NPs as carriers for drug delivery into the brain, HSA NPs were studied by Otzen and coworkers in order to assess the nature of their interaction with $\alpha \mathrm{S}$ [80]. HSA NPs were produced as unmodified or polyethyleneimine(PEI)-functionalized $\sim 35-40 \mathrm{~nm}$ spherical particles. By use of a centrifugation assay, fluorescence anisotropy measurements and small-angle X-ray scattering (SAXS) data, the authors found that $\alpha \mathrm{S}$ was attracted much more strongly to positively charged PEI-HSA NPs than to negatively charged HSA NPs. Changes in the CD spectral shape suggested that the interaction with PEI-HSA NPs caused a conformational change in $\alpha$ S. The absence of a significant binding to HSA NPs, despite their net negative surface charge, may suggest that interactions with biological NPs are distinct relative to most synthetic platforms because the former exhibit an inhomogeneous distribution of polar, charged and nonpolar groups as opposed to the generally isotropic presence of chemical groups on the surface of common synthetized NPs.

\section{Influence of Nanoparticles on Alpha-Synuclein Aggregate Formation}

\subsection{General Surface Effects on Aggregation Kinetics}

$\alpha \mathrm{S}$ fibrillation is commonly considered a nucleation-dependent growth process that follows sigmoidal kinetics with distinct phases of nucleation, propagation and equilibration [81,82] (Figure 3A,B). The primary nucleation step (commonly associated with the lag-phase), during which soluble species are sequestered into oligomers of different sizes and structures, is much slower compared to the addition of monomers to preformed protofibrils, which leads to an exponential growth of fibrils (growth, propagation or elongation phase) until a state of equilibrium is achieved (plateau phase). This simplified two-step model adequately describes the evolution of the system from a macroscopic point of view, however it does not consider the multitude of microscopic events that contribute to the entire process. It is now established that simultaneous microscopic processes are ongoing during all 
phases and that processes other than primary nucleation and growth, such as fibril fragmentation or secondary nucleation, may represent important events during aggregation [83-85]. On-pathway and off-pathway intermediate supramolecular assemblies exhibit different degrees of cytotoxicity, however their identification and characterization remains challenging $[81,86]$. Due to the complexity of the aggregation phenomenon and the difficulty to access microscopic events, most studies involving perturbations of $\alpha \mathrm{S}$ aggregation focus on comparative analyses of the kinetics at the macroscopic level. Experimentally, kinetics curves are generated by following time-dependent changes in sample turbidity or the fluorescence intensity of fibril-responsive dyes, such as Thioflavin $\mathrm{T}$ or by means of several other biochemical and biophysical techniques [21].

A

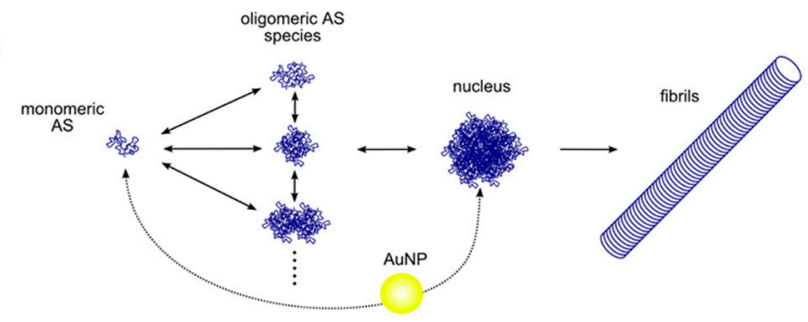

C
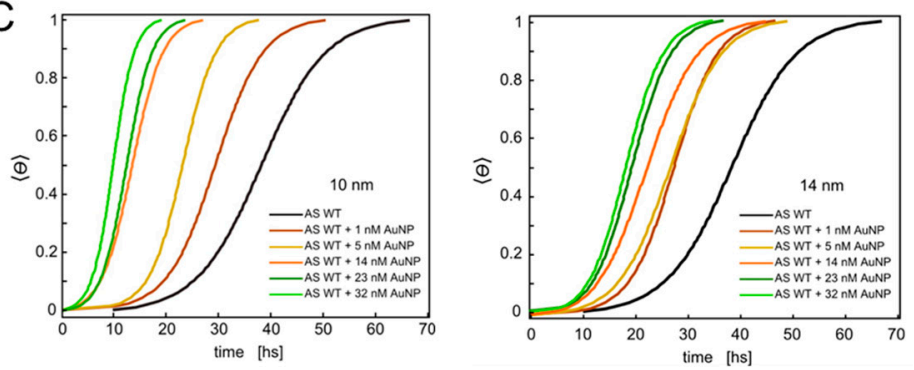

B
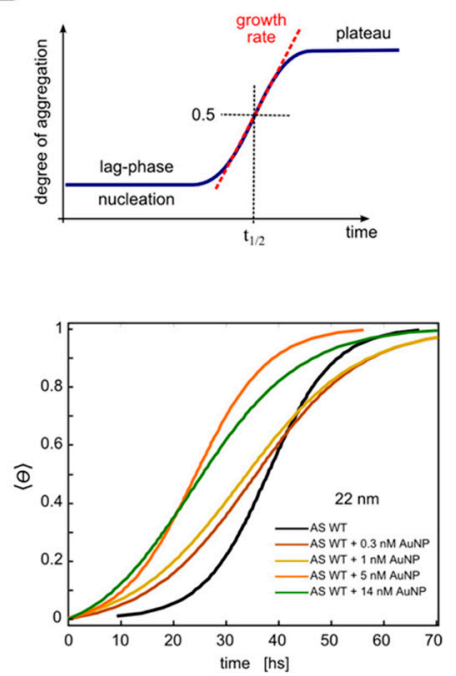

Figure 3. Nanoparticle-induced perturbation of fibril formation kinetics. (A) Schematic of the aggregation process of $\alpha \mathrm{S}$. AuNPs may interact with monomeric and/or oligomeric $\alpha \mathrm{S}$ during the process of nucleation. (B) Diagram of the sigmoidal kinetics corresponding to nucleation followed by fast, autocatalytic growth. (C) Average $\theta(t)$ for samples with different concentrations of AuNPs with diameters of 10,14 and $22 \mathrm{~nm}$, respectively. $\theta(\mathrm{t})$ is the aggregate-responsive spectroscopic observable. Adapted with permission from Álvarez et al. Nano Lett, 2013, 13 (12) 6156-6163. Copyright 2013 American Chemical Society.

Surfaces have a profound impact on aggregation phenomena [42,87]. It has long been recognized that lipid membrane surfaces can act as catalysts of fibril formation, serving as a platform for nucleation and further polymerization $[88,89]$. Actually, membrane binding of $\alpha \mathrm{S}$ appears to be an important factor in the pathogenesis of Parkinson's disease [90]. Membrane-assisted aggregation could result from several concurrent factors, including a reduction of conformational entropy in the bound state, the induction of structural ordering, surface molecular crowding effects and lowering of the local dielectric constant which may facilitate the formation of intermolecular contacts [91-93]. The notion that surfaces may facilitate fibril formation is frequently exploited in in vitro aggregation studies of certain IDPs, including $\alpha \mathrm{S}$, which display extremely slow aggregation kinetics in solution. The addition of beads or other surfaces imparts a dramatic acceleration on protein self-assembly, allowing to perform experiments in practical time frames. Fibril seeds themselves offer particularly active surfaces that catalyze nucleation of aggregation-resistant proteins. Based on these evidences, NPs have attracted much interest owing to their high surface-to-volume ratio [94], compared to bulk material and many studies have been carried out on the effects of NPs on the aggregation of amyloidogenic proteins [22]. It emerges that NPs can lead to either acceleration or retardation of the fibril formation, depending on several factors such as the physicochemical properties of the NPs (e.g., size, charge, nature of exposed chemical groups), the amino acid composition and stability of the IDP, the concentrations of the solutes 
and the characteristics of the solution (e.g., ionic strength, $\mathrm{pH}$ ) [95]. Thus, proper tuning of the NP properties shows promise as a means to control fibril formation pathways and could eventually provide a novel strategy for therapeutic intervention against aberrant protein aggregation in neurological disorders. Nonetheless, it must be considered that NP properties will also determine their ability to cross the blood-brain barrier and the cellular membranes before reaching the neuronal cytosol. Available pathways and strategies adopted to deliver NPs across the blood-brain barrier have been recently reviewed [96] and significant progress has been made in understanding the factors that control cellular uptake of NPs $[97,98]$. Most of the case studies presented here aimed at probing specific surface effects on protein aggregation and often did not address the ability of NPs to cross biological barriers.

A growing number of NP materials have been tested for their capability to influence the fibril formation process of $\alpha \mathrm{S}$. They include metals ( $\mathrm{Au}, \mathrm{Fe})[41,99,100]$, metal/metalloid oxides $\left(\mathrm{CeO}_{2}, \mathrm{TiO}_{2}\right.$, $\mathrm{ZnO}, \mathrm{Fe}_{3} \mathrm{O}_{4}, \mathrm{SiO}_{2}$ ) [37,38,44,101-104], carbon (graphene, fullerenol) [44,105,106], polymers (dendrimers, others) [42,107-111], biomolecules (protein-based) [80,112] and lipids (detergent, phospholipid) [74, 113-115]. The diversity of sizes, surface groups, charge density, hydrophobicity/hydrophilicity and other features of the investigated particles, render the rationalization of the results a challenging task. For example, both negatively and positively charged NPs were reported to inhibit $\alpha$ S fibrillation and both types were found to accelerate the process. In this regard, it appears that in order to establish more general paradigms, studies on a single protein/NP pair are of limited use, while more systematic investigations would be more informative. Furthermore, we emphasize the importance of conducting kinetics experiments with extreme rigor (e.g., avoiding NP precipitation, performing several replicas) and of carefully reporting the conditions in which experiments were performed (solution conditions, solute concentrations, mechanical agitation, etc.), to ensure that results can be compared and interpreted correctly.

A systematic study of the interaction between $\alpha \mathrm{S}$ and citrate-capped AuNPs in a range of sizes $(10,14$ and $22 \mathrm{~nm})$ and of concentrations was carried out by Stefani and coworkers [41]. To monitor the evolution of the aggregation process at a macroscopic level, the team adopted an approach based on the use of the environment-sensitive fluorescent probe MFC, covalently attached to an engineered $\alpha \mathrm{S}$. This dual-emission dye is a multiparametric fluorescent probe, highly sensitive to changes in polarity and hence an exquisite reporter of early protein aggregation events [116]. The aggregation kinetics of $\alpha \mathrm{S}$ in the presence of NPs followed a sigmoidal trend, exhibiting a transition halftime that decreased with the increase of AuNP concentration (Figure 3C). The overall acceleration produced by the AuNPs could be traced back to distinct effects on the nucleation and growth phases. For smaller AuNPs, the growth rate increased with particle concentration, while such effect was not observed with the $22 \mathrm{~nm}$ AuNPs. Instead, the latter had a more pronounced effect on the duration of the lag phase. The observed effects on the transition halftime and the growth rate did not scale with the available surface area. The authors attributed the reduction of the lag phase to the accumulation of protein on the AuNP surface, promoting the formation of critical nuclei for fibrillization. They further explained the variations in growth rate as a function of AuNP size by the formation of nuclei of different nature. This study therefore illustrates that the impact of NPs on the aggregation of $\alpha \mathrm{S}$ is often not linear with some property of the NPs but multifaceted, underscoring the complexity of microscopic interactions occurring at the nano-bio interface.

\subsection{Mechanistic Insights into Nanoparticle-Mediated Perturbations of aS Aggregation}

A mechanistic description of the effects of surfaces on the aggregation kinetics of polypeptides requires consideration of the concurring microscopic events. In this respect, several available strategies may prove useful, such as the global analysis of macroscopic aggregation curves measured under different conditions [117], computational methods that take into account the structural plasticity of the polypeptide as well as the nature of the NP surface $[117,118]$ and experimental procedures that allow the observation of structural transitions or the detection of transient intermediates. To date, a limited number of such studies have been applied to $\alpha \mathrm{S} / \mathrm{NP}$ systems. 
The consideration that certain NPs accelerate protein aggregation, while others cause a retardation of fibril formation, prompted Linse and coworkers to explore which factors were responsible for one or the other behavior [42]. By use of a dynamic Monte Carlo method, the group simulated amyloid growth profiles in the presence of surfaces with varying attraction potential. The results showed that weakly attractive surfaces (peptide binding constant, $\mathrm{K}=0.0017 \mu \mathrm{M}^{-1}$ ) determined a reduction of the nucleation rate, compared to non-attractive surfaces, while highly attractive surfaces $\left(\mathrm{K}=0.16 \mu \mathrm{M}^{-1}\right)$ accelerated the nucleation process. Indeed, weakly attractive objects simply reduce the concentration of free monomers available to form aggregation nuclei in solution but they do not change the microscopic events. By contrast, on the surface of highly attractive materials, distinct nuclei are formed in addition to those that form in solution. In the case of an intermediate attraction potential, the apparent kinetics was similar to that occurring with non-attractive surfaces, however the structures of the initial aggregates were different. Interestingly, the above observations were modulated by the intrinsic properties of the polypeptide, whereby for example weakly attractive surfaces retarded fibril formation by aggregation-prone mutants but accelerated the process for more stable polypeptides. ThT fluorescence assays performed using plain polystyrene NPs and $\alpha$ S consistently showed an acceleration of fibril growth upon increasing NP concentration, as a consequence of a strong non-electrostatic attraction causing surface-catalyzed nucleation. In general, it seems possible that positively and negatively charged NPs could exert the same inhibitory or acceleratory effect on the fibrillization of $\alpha S$, because they would establish electrostatic interactions with either the acidic C-terminal or the basic N-terminal domains [56]. Neutral objects were reported to have limited impact on the aggregation rate, presumably because they were not able to interact significantly with $\alpha \mathrm{S}$ [44].

While computational methods can capture the formation of early-stage aggregates and provide atomistic insights into conformational transitions with relative ease, the identification of transient intermediates and the detection of time-dependent structural changes during fibrillization remain experimentally challenging. Chattopadhyay and coworkers applied fluorescence correlation spectroscopy (FCS) and laser scanning microscopy (LSM) to investigate the early events of $\alpha S$ aggregation in the presence of pristine or Lys-modified $\mathrm{Fe}_{3} \mathrm{O}_{4}$ NPs [43]. The use of these techniques proved advantageous over the use of standard dye-based methods which are quite insensitive to the formation of smaller aggregation intermediates. Bare $\mathrm{Fe}_{3} \mathrm{O}_{4} \mathrm{NPs}$ were found to accelerate early and late-stage aggregation of $\alpha \mathrm{S}$, while Lys-coated $\mathrm{Fe}_{3} \mathrm{O}_{4}$ NPs displayed an inhibitory effect. Maximum entropy analysis of the correlation functions measured by FCS detected increases in conformational heterogeneity during the progress of aggregation and revealed the presence of aggregated species at earlier time points in the presence of bare $\mathrm{Fe}_{3} \mathrm{O}_{4} \mathrm{NPs}$. The early aggregates were visualized by LSM. The molecular basis for the different perturbations elicited by bare and Lys-coated particles remains elusive, however the study demonstrated the possibility of acquiring important information on aggregates in heterogeneous systems.

Hajipour and colleagues used size exclusion chromatography coupled with multi-angle light scattering (SEC-MALS) to quantify the amount of small $\alpha$ S oligomers formed in the presence of SPIONs or graphene nanoobjects and ranked the particles according to their ability to trigger the formation of such aggregates [44]. They were further able to determine whether the formed oligomers were on- or off-pathway with respect to fibrillization. In another study, Tira et al. followed the time course of $\alpha \mathrm{S}$ aggregation in the presence of SNPs using CD spectroscopy [38]. The authors could track the time-dependent structural transitions of the polypeptide from its native disordered state to conformations with mixed $\alpha$ and $\beta$ secondary elements. Interestingly, the shapes of CD spectra collected at different time points for $\alpha \mathrm{S}$ and its methionine-oxidized form in the presence of SNPs indicated that the two species formed distinct supramolecular assemblies, consistent with the reported resistance of the oxidized species to form fibrils [119]. Taken together, the information obtained from experiments on prefibrillar species could be used to inform computational methods and contribute to an improved description of the complex aggregation pathways. 


\subsection{Lipid Surface-Mediated $\alpha S$ Aggregation}

The nature of lipid surfaces is quite unique due to their soft, dynamic character which allows peptides to penetrate into the lipid layer(s), at least partially [120,121]. In addition, lipids and amyloidogenic polypeptides share an amphipathic structure and are therefore intrinsically prone to interact. The interactions are modulated by several factors and are highly dependent on lipid composition, surface charges and thermotropic properties [122,123]. Hence, the mechanisms by which lipid nanovesicles affect $\alpha \mathrm{S}$ fibril formation may depart from those involved with other nanomaterials. Indeed, the mode of association with lipid surfaces modulates $\alpha \mathrm{S}$ aggregation in different ways $[91,115,124,125]$. Furthermore, it has been suggested that fibrillization in the presence of lipid molecules may result in the formation of protein-lipid co-aggregates [126-128] and that the morphology of fibrils is modulated by the relative proportion of protein and lipids [129].

$\alpha \mathrm{S}$ partitions dynamically to SUVs and LUVs composed of anionic phospholipids such as phosphatidylserines $[39,123]$. Interestingly, the binding affinity is highest when the lipid layers are in the fluid state, as opposed to the gel-like state, since in the former case the hydrophobic portions of the lipid molecules are on average more exposed [123]. In turn, $\alpha$ S binding affects the lipid phase behavior and induces lipid segregation into protein-poor and protein-rich populations [123]. Yet, unexpectedly, the lipid phase state does not correlate with the vesicle-promoted acceleration of $\alpha \mathrm{S}$ amyloid fibril formation [123]. Instead, the kinetics of aggregation was found to correlate with the solubility of the lipid molecules, suggesting that at least part of the free energy barrier for the aggregation process is associated with the translocation of lipid molecules from a membrane to a protein environment [123].

Aggregation assays carried out under quiescent conditions and at varying dimyristoyl phosphatidylserine (DMPS) $/ \alpha \mathrm{S}$ ratios indicated that $\alpha \mathrm{S}$ did not convert into fibrils when excess lipid was present and most of the protein was in the bound state [39]. On the contrary, at lower lipid concentrations, when significant populations of both free and lipid-bound protein were established, SUVs determined the rapid formation of amyloid fibrils. Indeed, a combined experimental and theoretical analysis indicated that at low lipid/ $\alpha S$ ratios, the bound protein promoted a primary nucleation process, much faster than that occurring in bulk solution. The facilitated nucleation was attributed to the high local concentration of protein on the SUV surface and to a conformational shift towards aggregation-competent states [39]. Under the used conditions, other microscopic processes, including homogeneous primary nucleation, secondary nucleation and fragmentation, did not contribute measurably to the aggregation reaction. A similar finding was reported concerning the effect of nanovesicles made by zwitterionic lipids, which influenced the lag time more than the fibril elongation rate [113]. Under quiescent conditions, secondary processes may be prevented due to kinetic trapping of the lipid-bound fibrils [39]. Site-resolved NMR data obtained using nanodiscs as membrane models indicated that region-specific membrane affinities (particularly of the NAC region) were correlated with aggregation behavior [74]. The dual effect of lipid surfaces to both accelerate or inhibit $\alpha \mathrm{S}$ amyloid fibril formation depending on the relative proportion of protein and phospholipids may suggest a possible mechanism for the onset of aberrant aggregation as a consequence of altered levels of $\alpha \mathrm{S}$ expression, associated with some forms of PD [130].

It has been proposed that the transient interaction of $\alpha \mathrm{S}$ with lipid bilayers may determine the formation of a pool of helical conformers that are aggregation-resistant [131]. Thus, physiologically, lipid surfaces may act as chaperones that assist the folding process of otherwise disordered protein molecules. An imbalance in the relative populations of protein in the folded and unfolded pools may cause aberrant aggregation in pathology. These findings suggest the possibility to develop tailored $\mathrm{NPs}$ as artificial cofactors that assist the formation of aggregation-resistant $\alpha \mathrm{S}$ species.

\subsection{Nanoparticle-Fibril Interactions and Fibril Disassembly}

The removal of amyloid deposits is a prominent therapeutic aim in protein misfolding diseases [132]. However, the disassembly of preformed amyloid fibrils is both challenging and risky. On the one hand, protein fibrils are insoluble, extremely stable and resistant to degradation. On the other hand, 
disaggregation may exacerbate amyloid toxicity by increasing the load of toxic oligomers [133]. Thus, in order for NPs to be effective in reverting aberrant deposition of protein fibrils, they must display significant affinity for the fibrillar structures, establish interactions that weaken or disrupt the dense network of hydrogen bonds that stabilize the stacked $\beta$-strands and promote the conversion of fragments into harmless products. Diverse NPs were shown to interact with preformed $\alpha \mathrm{S}$ fibrils.

Citrate-capped AuNPs of the size of $22 \mathrm{~nm}$ but not of $14 \mathrm{~nm}$ and lower, were found to associate with fibrils, indicating a size-dependent affinity [41]. Mercapto-undecanesulfonate-coated AuNPs were developed to target synthetic, recombinant and native fibrils derived from different amyloidogenic proteins, including $\alpha \mathrm{S}$ [134]. Such particles did not exhibit fibril-disaggregating properties, instead they were exploited to label amyloid fibrils for assessing morphological polymorphism using cryogenic electron microscopy (cryo-EM) [134]. Both SPIONs and graphene were reported to disassemble $\alpha \mathrm{S}$ fibrils, with a higher efficacy shown by positively charged nano-objects, possibly related to their higher affinity to charged $\alpha \mathrm{S}$ residues [44]. Upon fibril fragmentation, the amount of oligomeric species did not increase, suggesting a safe use of these NPs [44].

In addition to graphene, also graphene quantum dots (GQDs) were shown to induce dissociation of $\alpha \mathrm{S}$ fibrils [40]. Ko and coworkers carried out a thorough characterization of this process [40]. GQDs produced the dissociation of fibrils into short fragments of an average length of $235 \mathrm{~nm}$ and $70 \mathrm{~nm}$ after 6 and $24 \mathrm{~h}$, respectively. After 3 days of incubation, the number of fragments decreased, indicating that the process progressed until complete disassembly. The interaction of the negatively charged GQDs with $\alpha \mathrm{S}$ was likely initiated by electrostatic attraction with the protein's N-terminal domain. MD simulations performed with the sole NAC domain indicated that after initial binding, the $\beta$-sheet structure of the outer monomer was rapidly and completely destroyed as a consequence of strong hydrophobic interactions between GQDs and valine residues. Importantly, GQDs could penetrate the blood-brain barrier and protect mice against dopamine neuron loss induced by preformed amyloid deposits.

Dendrimers have been recognized as potential powerful agents for the disaggregation of fibrils, displaying strong binding affinity to fibrillar structures and exerting their destructive effect by acting as efficient chaotropes [135]. Specifically, polyamidoamine (PAMAM) dendrimers were shown to interact with $\alpha S$ fibrils, the binding affinity increasing with the generation number $(G 4<\mathrm{G} 5<\mathrm{G6}$ ) [109]. The combined evidence from TEM, CD and ThT fluorescence indicated that dendrimers attacked the fibrils along the entire filament, not just at the ends and lead to amorphous aggregation. Similar to PAMAM dendrimers, also urea(U)- and methylthiourea(MTU)-modified polypropyleneimine (PPI) dendrimers were found to disaggregate preformed fibrils [136]. TEM detected the fragmentation of fibrils by G3-MTU-PPI into smaller and less organized aggregates. Interestingly, both types of NPs were found to significantly reduce the $\alpha$ S fibril load inside SK-MEL-5 cells in a dose-dependent and generation-dependent (MTU-PPI) or generation-independent (U-PPI) manner. However, MTU-PPI dendrimers displayed higher cytotoxicity in the presence of preformed $\alpha$ fibrils [136]. Further studies on the effects of dendrimers and other polymeric particles on $\alpha \mathrm{S}$ aggregation have been reviewed elsewhere [137].

\section{Alpha-Synuclein/Nanoparticle Conjugates and Hybrid Nanomaterials}

Functionalization or the combination of NPs with $\alpha$ S molecules has been intensely explored to produce nanobioconjugates and hybrid nanomaterials for diverse technological applications in bioanalytical chemistry and bionanotechnology $[45,138,139]$. Depending on the NP material and the aim of the application, a variety of conjugation strategies have been exploited, ranging from the simple deposition of the biomolecule on the NP surface [46,139], to non-covalent high affinity binding [45] and to covalent bond formation $[138,140]$. The conformational versatility of $\alpha S$ made it possible to exploit different properties of the associated molecules, from a disordered and highly dynamic form to the ordered superstructure typical of fibrils. Furthermore, protein self-assembly was exploited to fabricate ordered multi-component, supramolecular nanomaterials [46]. 
Jares-Erijman and coworkers explored the possibility to develop novel reactive agents or nanoactuators, based on the decoration of QDs with multiple copies of $\alpha S$ [45]. $\alpha S$ containing an A90C single point mutation was conjugated to biotin via maleimide chemistry, while QDs were capped with streptavidin. Thus, $\alpha \mathrm{S}-\mathrm{QD}$ nanoconjugates were obtained exploiting the formation of the well-known high affinity biotin-streptavidin complex. The nanoactuators were found to accelerate the formation of $\alpha \mathrm{S}$ amyloid fibrils, both in vitro and in live cells, thereby acting as artificial nucleation seeds. The catalytic effect was attributed to the self-assembly of the protein initiated by the high local concentrations displayed at the surface of the NPs. The developed system could facilitate cellular studies of amyloid formation.

The production of AuNP-biomolecule conjugates often exploits the spontaneous formation of ligand monolayers via unique bonds between the Au surface and sulfhydryl groups of the biomolecule. Paik and coworkers found that a thin shell of modified $\alpha \mathrm{S}$ molecules conjugated to AuNPs via Au-S bonds facilitated their deposition into a regular two-dimensional array on a glass support [138]. The obtained material constituted the basis for the production of a surface-enhanced Raman scattering biosensor. The platform was indeed responsive to phthalocyanine tetrasulfonate, an $\alpha S$ ligand and aggregation inhibitor and to metal ions forming complexes with the compound. The formation of a uniform array of coated AuNPs was attributed to the capability of fixed $\alpha S$ molecules to establish intermolecular interactions.

The $\alpha$ S-mediated assembly of AuNPs into hierarchical superstructures was further exploited to fabricate a flexible, free-standing NP monolayer film useful for the development of bio-integrated nano-devices and high-performance sensors [46] (Figure 4). Cysteine-free protein was first adsorbed onto AuNPs (10-30 nm) and subsequently onto a polycarbonate substrate. Fibril-like protein-protein linkages were revealed by scanning electron microscopy and $\beta$-sheet structure formation was observed by attenuated total reflectance Fourier transform infrared spectroscopy. The conversion into $\beta$ structures was probably triggered by the exposure of the protein-AuNP system to chloroform, necessary to release the film from the support. Importantly, the process was specific for $\alpha S$, as the film could not be obtained with other model protein molecules. An analogous concept was used to develop metal NP-based organic field-effect transistors with electrical memory [139]. A closely packed AuNP monolayer was obtained by the $\mathrm{pH}$-dependent adsorption of $\alpha \mathrm{S}$-AuNP conjugates on a $\mathrm{SiO}_{2}$ surface. Pentacene, a high-performance organic semiconductor, was finally deposited on the formed $\alpha \mathrm{S}-\mathrm{AuNP}$ film. The use of $\alpha \mathrm{S}$ proved invaluable for the optimal controllability over the hybrid material structures, allowing to obtain highly tunable memory performance.
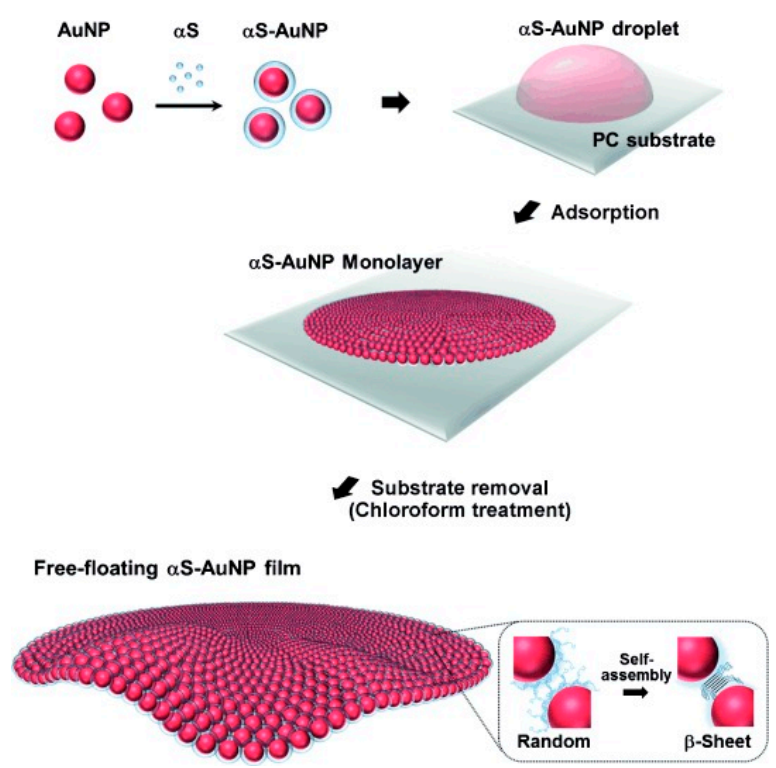

Figure 4. Production of functional $\alpha$ S-based nanobiocomposites. The fabrication of a free-floating 
$\alpha S$-AuNP monolayer film through the preparation of $\alpha$ S-coated AuNPs, adsorption of the $\alpha$ S-AuNPs onto the polycarbonate (PC) substrate and subsequent free-standing film production by $\alpha \mathrm{S}-\alpha \mathrm{S}$ self-assembly upon removal of the substrate with chloroform. Reproduced with permission from Lee et al. Angew Chem. Int. Ed., 2015, 54 (15), 4571-4576, (c) 2020 WILEY-VCH Verlag GmbH \& Co. KGaA, Weinheim.

Another study demonstrated the possibility to produce $\alpha$ S-based nanocomposites as intracellular drug delivery systems [140]. Mesoporous SNPs ( 100 nm size and pore diameter of 2-3 nm) were coated with AuNPs, previously functionalized with $\alpha$, to yield 'raspberry-type' particles-on-a-particle (PoP) structures. The anticancer agent rhodamine 6G, loaded into the PoPs, could be released upon exposure of the nanocomposite to the $\alpha$ S-binding cation $\mathrm{Ca}^{2+}$. Intracellular uptake of PoPs and drug release was demonstrated with HeLa cells in the presence of intracellular $\mathrm{Ca}^{2+}$-regulating agents. In this context, $\alpha S$ acted as a useful switch to open the gates of mesoporous SNPs by altering its conformation in a $\mathrm{Ca}^{2+}$-dependent manner.

Assembly of NPs into controllable nanoobjects expands their application potential for the development of nanoscale electronic and optical devices. Biopolymers have been shown to provide effective means for organizing NPs into superstructures and fibrillar structures have attracted considerable interest in this respect. For example, pea-pod-type chains of AuNPs embedded into dielectric $\alpha$ S fibrils were shown to exhibit photoconductivity with visible light [141]. The unit assembly strategy of amyloid fibril formation of $\alpha \mathrm{S}$ was employed to construct anisotropic one-dimensional chains of AuNPs within the amyloid fibrils. The necessary conformational transition of AuNP-adsorbed molecules from the disordered to the ordered state was induced by exposure of the assembly units to hexane or $\mathrm{pH}$ change. Interestingly, the morphological polymorphism of fibrillar structures obtained in different conditions could provide a means to fabricate chains of AuNPs with diverse organization. $\mathrm{NP}$ chains of $\mathrm{Pd}$ and $\mathrm{Cu}$ were also synthetized exploiting $\alpha \mathrm{S}$ fibrils as biopolymeric templates [142]. Finally, $\alpha S$ amyloid fibrils were found to drive a helical arrangement of gold nanorods [143]. The latter showed no apparent interaction with the monomeric protein but effective adsorption onto chiral fibril structures via noncovalent interactions. The helical arrangement resulted in intense optical activity at the surface plasmon resonance wavelengths, thereby constituting a novel sensing technique for the detection of fibrils.

\section{Conclusions}

We surveyed research works focused on the behavior of the small protein $\alpha$ S at the interface with NPs in an attempt to obtain a more defined picture of the factors that determine the protein-particle interactions and influence the conformational transitions of the biomolecule. Through a better understanding of $\alpha$ S-NP systems at the molecular level, we have moved forward towards the possibility of designing nanomaterials with useful functionalities for applications in diverse scientific and technological areas. A number of studies have demonstrated that it is possible to determine and even predict how $\alpha$ S interacts with different nanoscale surfaces, highlighting the multiple conformations that the polypeptide can adopt and describing how to control the interactions. It has emerged that electrostatic forces dictate the mode of adsorption of monomeric $\alpha S$ to diverse nanoscale surfaces, providing alternative anchors (the amphiphilic N-terminal or acidic C-terminal domains) for binding to negatively or positively charged NPs. Yet, hydrophobic attraction was shown to contribute to protein adsorption too, determining some involvement of the aggregation-promoting NAC domain. It has been shown that certain NPs are able to modify protein aggregation, with encouraging results regarding the possibility of redirecting the formation of neurotoxic aggregates towards more harmless species or even of disassembling otherwise intractable amyloid fibrils. The different exposure of amino acid residues in the monomeric, oligomeric and fibrillar states of $\alpha S$ may provide the basis for the selective targeting of toxic species by NPs. Finally, the extraordinary conformational plasticity of $\alpha S$ was exploited to design higher hierarchical structures that showed interesting novel physical or 
chemical attributes. The field of study continues to show extraordinary vivacity and it is expected that new therapeutic and technological solutions will be proposed in the near future.

Funding: This work received no external funding.

Acknowledgments: We thank all the members of the research group for stimulating discussions.

Conflicts of Interest: The authors declare no conflict of interest.

\section{References}

1. Breydo, L.; Wu, J.W.; Uversky, V.N. $\alpha$-Synuclein misfolding and Parkinson's disease. Biochim. Biophys. Acta Mol. Basis Dis. 2012, 1822, 261-285. [CrossRef] [PubMed]

2. Alderson, T.R.; Markley, J.L. Biophysical characterization of $\alpha$-synuclein and its controversial structure. Intrinsically Disord. Proteins 2013, 1, e26255. [CrossRef] [PubMed]

3. Maroteaux, L.; Campanelli, J.; Scheller, R. Synuclein: A neuron-specific protein localized to the nucleus and presynaptic nerve terminal. J. Neurosci. 1988, 8, 2804-2815. [CrossRef] [PubMed]

4. Cheng, F.; Vivacqua, G.; Yu, S. The role of alpha-synuclein in neurotransmission and synaptic plasticity. J. Chem. Neuroanat. 2011, 42, 242-248. [CrossRef]

5. Burre, J.; Sharma, M.; Tsetsenis, T.; Buchman, V.; Etherton, M.R.; Sudhof, T.C. $\alpha$-Synuclein Promotes SNARE-Complex Assembly in Vivo and in Vitro. Science 2010, 329, 1663-1667. [CrossRef]

6. Cabin, D.E.; Shimazu, K.; Murphy, D.; Cole, N.B.; Gottschalk, W.; McIlwain, K.L.; Orrison, B.; Chen, A.; Ellis, C.E.; Paylor, R.; et al. Synaptic Vesicle Depletion Correlates with Attenuated Synaptic Responses to Prolonged Repetitive Stimulation in Mice Lacking $\alpha$-Synuclein. J. Neurosci. 2002, 22, 8797-8807. [CrossRef]

7. Burré, J.; Sharma, M.; Südhof, T.C. Cell Biology and Pathophysiology of $\alpha$-Synuclein. Cold Spring Harb. Perspect. Med. 2018, 8, a024091. [CrossRef]

8. Spillantini, M.G.; Schmidt, M.L.; Lee, V.M.-Y.; Trojanowski, J.Q.; Jakes, R.; Goedert, M. $\alpha$-Synuclein in Lewy bodies. Nature 1997, 388, 839-840. [CrossRef]

9. Uéda, K.; Fukushima, H.; Masliah, E.; Xia, Y.; Iwai, A.; Yoshimoto, M.; Otero, D.A.; Kondo, J.; Ihara, Y.; Saitoh, T. Molecular cloning of cDNA encoding an unrecognized component of amyloid in Alzheimer disease. Proc. Natl. Acad. Sci. USA 1993, 90, 11282-11286. [CrossRef]

10. Lashuel, H.A.; Overk, C.R.; Oueslati, A.; Masliah, E. The many faces of $\alpha$-synuclein: From structure and toxicity to therapeutic target. Nat. Rev. Neurosci. 2013, 14, 38-48. [CrossRef]

11. Weinreb, P.H.; Zhen, W.; Poon, A.W.; Conway, K.A.; Lansbury, P.T. NACP, A Protein Implicated in Alzheimer's Disease and Learning, Is Natively Unfolded. Biochemistry 1996, 35, 13709-13715. [CrossRef] [PubMed]

12. Eliezer, D.; Kutluay, E.; Bussell, R.; Browne, G. Conformational properties of $\alpha$-synuclein in its free and lipid-associated states. J. Mol. Biol. 2001, 307, 1061-1073. [CrossRef] [PubMed]

13. Nath, A.; Sammalkorpi, M.; DeWitt, D.C.; Trexler, A.J.; Elbaum-Garfinkle, S.; O'Hern, C.S.; Rhoades, E. The Conformational Ensembles of $\alpha$-Synuclein and Tau: Combining Single-Molecule FRET and Simulations. Biophys. J. 2012, 103, 1940-1949. [CrossRef] [PubMed]

14. Ullman, O.; Fisher, C.K.; Stultz, C.M. Explaining the Structural Plasticity of $\alpha$-Synuclein. J. Am. Chem. Soc. 2011, 133, 19536-19546. [CrossRef]

15. Bartels, T.; Choi, J.G.; Selkoe, D.J. $\alpha$-Synuclein occurs physiologically as a helically folded tetramer that resists aggregation. Nature 2011, 477, 107-110. [CrossRef]

16. Wang, W.; Perovic, I.; Chittuluru, J.; Kaganovich, A.; Nguyen, L.T.T.; Liao, J.; Auclair, J.R.; Johnson, D.; Landeru, A.; Simorellis, A.K.; et al. A soluble $\alpha$-synuclein construct forms a dynamic tetramer. Proc. Natl. Acad. Sci. USA 2011, 108, 17797-17802. [CrossRef]

17. Dettmer, U.; Newman, A.J.; Luth, E.S.; Bartels, T.; Selkoe, D. In Vivo Cross-linking Reveals Principally Oligomeric Forms of $\alpha$-Synuclein and $\beta$-Synuclein in Neurons and Non-neural Cells. J. Biol. Chem. 2013, 288, 6371-6385. [CrossRef]

18. Gould, N.; Mor, D.E.; Lightfoot, R.; Malkus, K.; Giasson, B.; Ischiropoulos, H. Evidence of Native $\alpha$-Synuclein Conformers in the Human Brain. J. Biol. Chem. 2014, 289, 7929-7934. [CrossRef]

19. Theillet, F.-X.; Binolfi, A.; Bekei, B.; Martorana, A.; Rose, H.M.; Stuiver, M.; Verzini, S.; Lorenz, D.; van Rossum, M.; Goldfarb, D.; et al. Structural disorder of monomeric $\alpha$-synuclein persists in mammalian cells. Nature 2016, 530, 45-50. [CrossRef] 
20. Guerrero-Ferreira, R.; Taylor, N.M.; Mona, D.; Ringler, P.; Lauer, M.E.; Riek, R.; Britschgi, M.; Stahlberg, H. Cryo-EM structure of alpha-synuclein fibrils. eLife 2018, 7, e36402. [CrossRef]

21. Giehm, L.; Lorenzen, N.; Otzen, D.E. Assays for $\alpha$-synuclein aggregation. Methods 2011, 53, $295-305$. [CrossRef] [PubMed]

22. Mahmoudi, M.; Kalhor, H.R.; Laurent, S.; Lynch, I. Protein fibrillation and nanoparticle interactions: Opportunities and challenges. Nanoscale 2013, 5, 2570. [CrossRef] [PubMed]

23. Nel, A.E.; Mädler, L.; Velegol, D.; Xia, T.; Hoek, E.M.V.; Somasundaran, P.; Klaessig, F.; Castranova, V.; Thompson, M. Understanding biophysicochemical interactions at the nano-bio interface. Nat. Mater 2009, 8, 543-557. [CrossRef] [PubMed]

24. Verma, A.; Rotello, V.M. Surface recognition of biomacromolecules using nanoparticle receptors. Chem. Commun. 2005, 303-312. [CrossRef] [PubMed]

25. Stark, W.J. Nanoparticles in Biological Systems. Angew. Chem. Int. Ed. 2011, 50, 1242-1258. [CrossRef] [PubMed]

26. Zanzoni, S.; Ceccon, A.; Assfalg, M.; Singh, R.K.; Fushman, D.; D’Onofrio, M. Polyhydroxylated [60]fullerene binds specifically to functional recognition sites on a monomeric and a dimeric ubiquitin. Nanoscale 2015, 7 , 7197-7205. [CrossRef] [PubMed]

27. Bortot, A.; Zanzoni, S.; D’Onofrio, M.; Assfalg, M. Specific Interaction Sites Determine Differential Adsorption of Protein Structural Isomers on Nanoparticle Surfaces. Chem. A Eur. J. 2018, 24, 5911-5919. [CrossRef] [PubMed]

28. Roach, P.; Farrar, D.; Perry, C.C. Surface Tailoring for Controlled Protein Adsorption: Effect of Topography at the Nanometer Scale and Chemistry. J. Am. Chem. Soc. 2006, 128, 3939-3945. [CrossRef]

29. Davis, M.E.; Chen, Z.; Shin, D.M. Nanoparticle therapeutics: An emerging treatment modality for cancer. Nat. Rev. Drug Discov. 2008, 7, 771-782. [CrossRef]

30. Monopoli, M.P.; Åberg, C.; Salvati, A.; Dawson, K.A. Biomolecular coronas provide the biological identity of nanosized materials. Nat. Nanotechnol. 2012, 7,779-786. [CrossRef]

31. Fleischer, C.C.; Payne, C.K. Nanoparticle-Cell Interactions: Molecular Structure of the Protein Corona and Cellular Outcomes. Acc. Chem. Res. 2014, 47, 2651-2659. [CrossRef] [PubMed]

32. Roach, P.; Farrar, D.; Perry, C.C. Interpretation of Protein Adsorption: Surface-Induced Conformational Changes. J. Am. Chem. Soc. 2005, 127, 8168-8173. [CrossRef] [PubMed]

33. Lynch, I.; Dawson, K.A. Protein-nanoparticle interactions. Nano Today 2008, 3, 40-47. [CrossRef]

34. Rana, S.; Yeh, Y.-C.; Rotello, V.M. Engineering the nanoparticle-protein interface: Applications and possibilities. Curr. Opin. Chem. Biol. 2010, 14, 828-834. [CrossRef]

35. Sapsford, K.E.; Tyner, K.M.; Dair, B.J.; Deschamps, J.R.; Medintz, I.L. Analyzing Nanomaterial Bioconjugates: A Review of Current and Emerging Purification and Characterization Techniques. Anal. Chem. 2011, 83, 4453-4488. [CrossRef]

36. Yang, J.A.; Lin, W.; Woods, W.S.; George, J.M.; Murphy, C.J. $\alpha$-Synuclein's Adsorption, Conformation and Orientation on Cationic Gold Nanoparticle Surfaces Seeds Global Conformation Change. J. Phys. Chem. B 2014, 118, 3559-3571. [CrossRef]

37. Vitali, M.; Rigamonti, V.; Natalello, A.; Colzani, B.; Avvakumova, S.; Brocca, S.; Santambrogio, C.; Narkiewicz, J.; Legname, G.; Colombo, M.; et al. Conformational properties of intrinsically disordered proteins bound to the surface of silica nanoparticles. Biochim. Biophys. Acta Gen. Subj. 2018, 1862, 1556-1564. [CrossRef]

38. Tira, R.; De Cecco, E.; Rigamonti, V.; Santambrogio, C.; Barracchia, C.G.; Munari, F.; Romeo, A.; Legname, G.; Prosperi, D.; Grandori, R.; et al. Dynamic molecular exchange and conformational transitions of alpha-synuclein at the nano-bio interface. Int. J. Biol. Macromol. 2020, 154, 206-216. [CrossRef]

39. Galvagnion, C.; Buell, A.K.; Meisl, G.; Michaels, T.C.T.; Vendruscolo, M.; Knowles, T.P.J.; Dobson, C.M. Lipid vesicles trigger $\alpha$-synuclein aggregation by stimulating primary nucleation. Nat. Chem. Biol. 2015, 11, 229-234. [CrossRef]

40. Kim, D.; Yoo, J.M.; Hwang, H.; Lee, J.; Lee, S.H.; Yun, S.P.; Park, M.J.; Lee, M.; Choi, S.; Kwon, S.H.; et al. Graphene quantum dots prevent $\alpha$-synucleinopathy in Parkinson's disease. Nat. Nanotechnol. 2018, 13, 812-818. [CrossRef] 
41. Álvarez, Y.D.; Fauerbach, J.A.; Pellegrotti, J.V.; Jovin, T.M.; Jares-Erijman, E.A.; Stefani, F.D. Influence of Gold Nanoparticles on the Kinetics of $\alpha$-Synuclein Aggregation. Nano Lett. 2013, 13, 6156-6163. [CrossRef] [PubMed]

42. Vácha, R.; Linse, S.; Lund, M. Surface Effects on Aggregation Kinetics of Amyloidogenic Peptides. J. Am. Chem. Soc. 2014, 136, 11776-11782. [CrossRef] [PubMed]

43. Joshi, N.; Basak, S.; Kundu, S.; De, G.; Mukhopadhyay, A.; Chattopadhyay, K. Attenuation of the Early Events of $\alpha$-Synuclein Aggregation: A Fluorescence Correlation Spectroscopy and Laser Scanning Microscopy Study in the Presence of Surface-Coated $\mathrm{Fe}_{3} \mathrm{O}_{4}$ Nanoparticles. Langmuir 2015, 31, 1469-1478. [CrossRef] [PubMed]

44. Mohammad-Beigi, H.; Hosseini, A.; Adeli, M.; Ejtehadi, M.R.; Christiansen, G.; Sahin, C.; Tu, Z.; Tavakol, M.; Dilmaghani-Marand, A.; Nabipour, I.; et al. Mechanistic Understanding of the Interactions between Nano-Objects with Different Surface Properties and $\alpha$-Synuclein. ACS Nano 2019, 13, 3243-3256. [CrossRef]

45. Roberti, M.J.; Morgan, M.; Menéndez, G.; Pietrasanta, L.I.; Jovin, T.M.; Jares-Erijman, E.A. Quantum Dots As Ultrasensitive Nanoactuators and Sensors of Amyloid Aggregation in Live Cells. J. Am. Chem. Soc. 2009, 131, 8102-8107. [CrossRef]

46. Lee, J.; Bhak, G.; Lee, J.-H.; Park, W.; Lee, M.; Lee, D.; Jeon, N.L.; Jeong, D.H.; Char, K.; Paik, S.R. Free-Standing Gold-Nanoparticle Monolayer Film Fabricated by Protein Self-Assembly of $\alpha$-Synuclein. Angew. Chem. Int. Ed. 2015, 54, 4571-4576. [CrossRef]

47. Assfalg, M.; Ragona, L.; Pagano, K.; D’Onofrio, M.; Zanzoni, S.; Tomaselli, S.; Molinari, H. The study of transient protein-nanoparticle interactions by solution NMR spectroscopy. Biochim. Biophys. Acta Proteins Proteom. 2016, 1864, 102-114. [CrossRef]

48. Randika Perera, Y.; Hill, R.A.; Fitzkee, N.C. Protein Interactions with Nanoparticle Surfaces: Highlighting Solution NMR Techniques. ISR J. Chem. 2019, 59, 962-979. [CrossRef]

49. Xie, M.; Hansen, A.L.; Yuan, J.; Brüschweiler, R. Residue-Specific Interactions of an Intrinsically Disordered Protein with Silica Nanoparticles and Their Quantitative Prediction. J. Phys. Chem. C 2016, 120, 24463-24468. [CrossRef]

50. Xie, M.; Li, D.; Yuan, J.; Hansen, A.L.; Brüschweiler, R. Quantitative Binding Behavior of Intrinsically Disordered Proteins to Nanoparticle Surfaces at Individual Residue Level. Chem. A Eur. J. 2018, 24, 16997-17001. [CrossRef]

51. Li, D.-W.; Xie, M.; Brüschweiler, R. Quantitative Cooperative Binding Model for Intrinsically Disordered Proteins Interacting with Nanomaterials. J. Am. Chem. Soc. 2020, 142, 10730-10738. [CrossRef] [PubMed]

52. Henzler, K.; Haupt, B.; Rosenfeldt, S.; Harnau, L.; Narayanan, T.; Ballauff, M. Interaction strength between proteins and polyelectrolyte brushes: A small angle X-ray scattering study. Phys. Chem. Chem. Phys. 2011, 13, 17599. [CrossRef] [PubMed]

53. Clemments, A.M.; Botella, P.; Landry, C.C. Spatial Mapping of Protein Adsorption on Mesoporous Silica Nanoparticles by Stochastic Optical Reconstruction Microscopy. J. Am. Chem. Soc. 2017, 139, 3978-3981. [CrossRef] [PubMed]

54. Shang, L.; Nienhaus, G.U. In Situ Characterization of Protein Adsorption onto Nanoparticles by Fluorescence Correlation Spectroscopy. Acc. Chem. Res. 2017, 50, 387-395. [CrossRef]

55. Yang, J.A.; Johnson, B.J.; Wu, S.; Woods, W.S.; George, J.M.; Murphy, C.J. Study of Wild-Type $\alpha$-Synuclein Binding and Orientation on Gold Nanoparticles. Langmuir 2013, 29, 4603-4615. [CrossRef]

56. Lin, W.; Insley, T.; Tuttle, M.D.; Zhu, L.; Berthold, D.A.; Král, P.; Rienstra, C.M.; Murphy, C.J. Control of Protein Orientation on Gold Nanoparticles. J. Phys. Chem. C 2015, 119, 21035-21043. [CrossRef]

57. Iwai, A.; Masliah, E.; Yoshimoto, M.; Ge, N.; Flanagan, L.; Rohan de Silva, H.A.; Kittel, A.; Saitoh, T. The precursor protein of non-A $\beta$ component of Alzheimer's disease amyloid is a presynaptic protein of the central nervous system. Neuron 1995, 14, 467-475. [CrossRef]

58. Kahle, P.J.; Neumann, M.; Ozmen, L.; Müller, V.; Jacobsen, H.; Schindzielorz, A.; Okochi, M.; Leimer, U.; van der Putten, H.; Probst, A.; et al. Subcellular Localization of Wild-Type and Parkinson's Disease-Associated Mutant $\alpha$-Synuclein in Human and Transgenic Mouse Brain. J. Neurosci. 2000, 20, 6365-6373. [CrossRef]

59. Jensen, P.H.; Nielsen, M.S.; Jakes, R.; Dotti, C.G.; Goedert, M. Binding of $\alpha$-Synuclein to Brain Vesicles Is Abolished by Familial Parkinson's Disease Mutation. J. Biol. Chem. 1998, 273, 26292-26294. [CrossRef]

60. Perez, R.G.; Waymire, J.C.; Lin, E.; Liu, J.J.; Guo, F.; Zigmond, M.J. A Role for $\alpha$-Synuclein in the Regulation of Dopamine Biosynthesis. J. Neurosci. 2002, 22, 3090-3099. [CrossRef] 
61. Davidson, W.S.; Jonas, A.; Clayton, D.F.; George, J.M. Stabilization of $\alpha$-Synuclein Secondary Structure upon Binding to Synthetic Membranes. J. Biol. Chem. 1998, 273, 9443-9449. [CrossRef] [PubMed]

62. Perrin, R.J.; Woods, W.S.; Clayton, D.F.; George, J.M. Interaction of Human $\alpha$-Synuclein and Parkinson's Disease Variants with Phospholipids: Structural analysis using site-directed mutagenesis. J. Biol. Chem. 2000, 275, 34393-34398. [CrossRef]

63. Chandra, S.; Chen, X.; Rizo, J.; Jahn, R.; Südhof, T.C. A Broken $\alpha$-Helix in Folded $\alpha$-Synuclein. J. Biol. Chem. 2003, 278, 15313-15318. [CrossRef] [PubMed]

64. Beyer, K. Mechanistic aspects of Parkinson's disease: $\alpha$-synuclein and the biomembrane. Cell Biochem. Biophys. 2007, 47, 285-299. [CrossRef] [PubMed]

65. Bussell, R.; Eliezer, D. A Structural and Functional Role for 11-mer Repeats in $\alpha$-Synuclein and Other Exchangeable Lipid Binding Proteins. J. Mol. Biol. 2003, 329, 763-778. [CrossRef]

66. Bisaglia, M.; Tessari, I.; Pinato, L.; Bellanda, M.; Giraudo, S.; Fasano, M.; Bergantino, E.; Bubacco, L.; Mammi, S. A Topological Model of the Interaction between $\alpha$-Synuclein and Sodium Dodecyl Sulfate Micelles. Biochemistry 2005, 44, 329-339. [CrossRef]

67. Ulmer, T.S.; Bax, A.; Cole, N.B.; Nussbaum, R.L. Structure and Dynamics of Micelle-bound Human-Synuclein. J. Biol. Chem. 2005, 280, 9595-9603. [CrossRef]

68. Jao, C.C.; Hegde, B.G.; Chen, J.; Haworth, I.S.; Langen, R. Structure of membrane-bound $\alpha$-synuclein from site-directed spin labeling and computational refinement. Proc. Natl. Acad. Sci. USA 2008, 105, 19666-19671. [CrossRef]

69. Trexler, A.J.; Rhoades, E. $\alpha$-Synuclein Binds Large Unilamellar Vesicles as an Extended Helix. Biochemistry 2009, 48, 2304-2306. [CrossRef]

70. Drescher, M.; Veldhuis, G.; van Rooijen, B.D.; Milikisyants, S.; Subramaniam, V.; Huber, M. Antiparallel Arrangement of the Helices of Vesicle-Bound $\alpha$-Synuclein. J. Am. Chem. Soc. 2008, 130, 7796-7797. [CrossRef]

71. Ferreon, A.C.M.; Gambin, Y.; Lemke, E.A.; Deniz, A.A. Interplay of $\alpha$-synuclein binding and conformational switching probed by single-molecule fluorescence. Proc. Natl. Acad. Sci. USA 2009, 106, 5645-5650. [CrossRef] [PubMed]

72. Georgieva, E.R.; Ramlall, T.F.; Borbat, P.P.; Freed, J.H.; Eliezer, D. The Lipid-binding Domain of Wild Type and Mutant $\alpha$-Synuclein: Compactness and interconversion between the broken and extended helix forms. J. Biol. Chem. 2010, 285, 28261-28274. [CrossRef] [PubMed]

73. Bodner, C.R.; Dobson, C.M.; Bax, A. Multiple Tight Phospholipid-Binding Modes of $\alpha$-Synuclein Revealed by Solution NMR Spectroscopy. J. Mol. Biol. 2009, 390, 775-790. [CrossRef] [PubMed]

74. Viennet, T.; Wördehoff, M.M.; Uluca, B.; Poojari, C.; Shaykhalishahi, H.; Willbold, D.; Strodel, B.; Heise, H.; Buell, A.K.; Hoyer, W.; et al. Structural insights from lipid-bilayer nanodiscs link $\alpha$-Synuclein membrane-binding modes to amyloid fibril formation. Commun. Biol. 2018, 1, 44. [CrossRef]

75. Rhoades, E.; Ramlall, T.F.; Webb, W.W.; Eliezer, D. Quantification of $\alpha$-Synuclein Binding to Lipid Vesicles Using Fluorescence Correlation Spectroscopy. Biophys. J. 2006, 90, 4692-4700. [CrossRef]

76. Kubo, S.; Nemani, V.M.; Chalkley, R.J.; Anthony, M.D.; Hattori, N.; Mizuno, Y.; Edwards, R.H.; Fortin, D.L. A Combinatorial Code for the Interaction of $\alpha$-Synuclein with Membranes. J. Biol. Chem. 2005, 280, 31664-31672. [CrossRef]

77. Eichmann, C.; Campioni, S.; Kowal, J.; Maslennikov, I.; Gerez, J.; Liu, X.; Verasdonck, J.; Nespovitaya, N.; Choe, S.; Meier, B.H.; et al. Preparation and Characterization of Stable $\alpha$-Synuclein Lipoprotein Particles. J. Biol. Chem. 2016, 291, 8516-8527. [CrossRef]

78. Chung, P.J.; Zhang, Q.; Hwang, H.L.; Leong, A.; Maj, P.; Szczygiel, R.; Dufresne, E.M.; Narayanan, S.; Adams, E.J.; Lee, K.Y.C. $\alpha$-Synuclein Sterically Stabilizes Spherical Nanoparticle-Supported Lipid Bilayers. ACS Appl. Bio Mater. 2019, 2, 1413-1419. [CrossRef]

79. McClain, S.M.; Ojoawo, A.M.; Lin, W.; Rienstra, C.M.; Murphy, C.J. Interaction of Alpha-Synuclein and Its Mutants with Rigid Lipid Vesicle Mimics of Varying Surface Curvature. ACS Nano 2020, 14, 10153-10167. [CrossRef]

80. Mohammad-Beigi, H.; Shojaosadati, S.A.; Marvian, A.T.; Pedersen, J.N.; Klausen, L.H.; Christiansen, G.; Pedersen, J.S.; Dong, M.; Morshedi, D.; Otzen, D.E. Strong interactions with polyethylenimine-coated human serum albumin nanoparticles (PEI-HSA NPs) alter $\alpha$-synuclein conformation and aggregation kinetics. Nanoscale 2015, 7, 19627-19640. [CrossRef] 
81. Cremades, N.; Cohen, S.I.A.; Deas, E.; Abramov, A.Y.; Chen, A.Y.; Orte, A.; Sandal, M.; Clarke, R.W.; Dunne, P.; Aprile, F.A.; et al. Direct Observation of the Interconversion of Normal and Toxic Forms of $\alpha$-Synuclein. Cell 2012, 149, 1048-1059. [CrossRef] [PubMed]

82. Iljina, M.; Garcia, G.A.; Horrocks, M.H.; Tosatto, L.; Choi, M.L.; Ganzinger, K.A.; Abramov, A.Y.; Gandhi, S.; Wood, N.W.; Cremades, N.; et al. Kinetic model of the aggregation of alpha-synuclein provides insights into prion-like spreading. Proc. Natl. Acad. Sci. USA 2016, 113, E1206-E1215. [CrossRef] [PubMed]

83. Cohen, S.I.A.; Vendruscolo, M.; Welland, M.E.; Dobson, C.M.; Terentjev, E.M.; Knowles, T.P.J. Nucleated polymerization with secondary pathways. I. Time evolution of the principal moments. J. Chem. Phys. 2011, 135, 065105. [CrossRef] [PubMed]

84. Cohen, S.I.A.; Vendruscolo, M.; Dobson, C.M.; Knowles, T.P.J. From Macroscopic Measurements to Microscopic Mechanisms of Protein Aggregation. J. Mol. Biol. 2012, 421, 160-171. [CrossRef] [PubMed]

85. Knowles, T.P.J.; Waudby, C.A.; Devlin, G.L.; Cohen, S.I.A.; Aguzzi, A.; Vendruscolo, M.; Terentjev, E.M.; Welland, M.E.; Dobson, C.M. An Analytical Solution to the Kinetics of Breakable Filament Assembly. Science 2009, 326, 1533-1537. [CrossRef] [PubMed]

86. Fauerbach, J.A.; Yushchenko, D.A.; Shahmoradian, S.H.; Chiu, W.; Jovin, T.M.; Jares-Erijman, E.A. Supramolecular Non-Amyloid Intermediates in the Early Stages of $\alpha$-Synuclein Aggregation. Biophys. J. 2012, 102, 1127-1136. [CrossRef] [PubMed]

87. Rabe, M.; Soragni, A.; Reynolds, N.P.; Verdes, D.; Liverani, E.; Riek, R.; Seeger, S. On-Surface Aggregation of $\alpha$-Synuclein at Nanomolar Concentrations Results in Two Distinct Growth Mechanisms. ACS Chem. Neurosci. 2013, 4, 408-417. [CrossRef]

88. Aisenbrey, C.; Borowik, T.; Byström, R.; Bokvist, M.; Lindström, F.; Misiak, H.; Sani, M.-A.; Gröbner, G. How is protein aggregation in amyloidogenic diseases modulated by biological membranes? Eur. Biophys. J. 2008, 37, 247-255. [CrossRef]

89. Relini, A.; Cavalleri, O.; Rolandi, R.; Gliozzi, A. The two-fold aspect of the interplay of amyloidogenic proteins with lipid membranes. Chem. Phys. Lipids 2009, 158, 1-9. [CrossRef]

90. Selkoe, D.J. Cell biology of protein misfolding: The examples of Alzheimer's and Parkinson's diseases. Nat. Cell Biol. 2004, 6, 1054-1061. [CrossRef]

91. Butterfield, S.M.; Lashuel, H.A. Amyloidogenic Protein-Membrane Interactions: Mechanistic Insight from Model Systems. Angew. Chem. Int. Ed. 2010, 49, 5628-5654. [CrossRef] [PubMed]

92. Hebda, J.A.; Miranker, A.D. The Interplay of Catalysis and Toxicity by Amyloid Intermediates on Lipid Bilayers: Insights from Type II Diabetes. Annu. Rev. Biophys. 2009, 38, 125-152. [CrossRef] [PubMed]

93. Byström, R.; Aisenbrey, C.; Borowik, T.; Bokvist, M.; Lindström, F.; Sani, M.-A.; Olofsson, A.; Gröbner, G. Disordered Proteins: Biological Membranes as Two-Dimensional Aggregation Matrices. Cell Biochem. Biophys. 2008, 52, 175-189. [CrossRef] [PubMed]

94. Linse, S.; Cabaleiro-Lago, C.; Xue, W.-F.; Lynch, I.; Lindman, S.; Thulin, E.; Radford, S.E.; Dawson, K.A. Nucleation of protein fibrillation by nanoparticles. Proc. Natl. Acad. Sci. USA 2007, 104, 8691-8696. [CrossRef] [PubMed]

95. Sauvage, F.; Schymkowitz, J.; Rousseau, F.; Schmidt, B.Z.; Remaut, K.; Braeckmans, K.; De Smedt, S.C. Nanomaterials to avoid and destroy protein aggregates. Nano Today 2020, 31, 100837. [CrossRef]

96. Lombardo, S.M.; Schneider, M.; Türeli, A.E.; Günday Türeli, N. Key for crossing the BBB with nanoparticles: The rational design. Beilstein J. Nanotechnol. 2020, 11, 866-883. [CrossRef]

97. Behzadi, S.; Serpooshan, V.; Tao, W.; Hamaly, M.A.; Alkawareek, M.Y.; Dreaden, E.C.; Brown, D.; Alkilany, A.M.; Farokhzad, O.C.; Mahmoudi, M. Cellular uptake of nanoparticles: Journey inside the cell. Chem. Soc. Rev. 2017, 46, 4218-4244. [CrossRef]

98. Donahue, N.D.; Acar, H.; Wilhelm, S. Concepts of nanoparticle cellular uptake, intracellular trafficking and kinetics in nanomedicine. Adv. Drug Deliv. Rev. 2019, 143, 68-96. [CrossRef]

99. Tahaei Gilan, S.S.; Yahya Rayat, D.; Ahmed Mustafa, T.; Aziz, F.M.; Shahpasand, K.; Akhtari, K.; Salihi, A.; Abou-Zied, O.K.; Falahati, M. $\alpha$-synuclein interaction with zero-valent iron nanoparticles accelerates structural rearrangement into amyloid-susceptible structure with increased cytotoxic tendency. Int. J. Nanomed. 2019, 14, 4637-4648. [CrossRef]

100. Gao, G.; Chen, R.; He, M.; Li, J.; Li, J.; Wang, L.; Sun, T. Gold nanoclusters for Parkinson's disease treatment. Biomaterials 2019, 194, 36-46. [CrossRef] 
101. Asthana, S.; Bhattacharyya, D.; Kumari, S.; Nayak, P.S.; Saleem, M.; Bhunia, A.; Jha, S. Interaction with zinc oxide nanoparticle kinetically traps $\alpha$-synuclein fibrillation into off-pathway non-toxic intermediates. Int. J. Biol. Macromol. 2020, 150, 68-79. [CrossRef] [PubMed]

102. Zand, Z.; Afarinesh Khaki, P.; Salihi, A.; Sharifi, M.; Qadir Nanakali, N.M.; Alasady, A.A.; Mohammad Aziz, F.; Shahpasand, K.; Hasan, A.; Falahati, M. Cerium oxide NPs mitigate the amyloid formation of $\alpha$-synuclein and associated cytotoxicity. Int. J. Nanomed. 2019, 14, 6989-7000. [CrossRef] [PubMed]

103. Ruotolo, R.; De Giorgio, G.; Minato, I.; Bianchi, M.; Bussolati, O.; Marmiroli, N. Cerium Oxide Nanoparticles Rescue $\alpha$-Synuclein-Induced Toxicity in a Yeast Model of Parkinson's Disease. Nanomaterials 2020, 10, 235. [CrossRef] [PubMed]

104. Taebnia, N.; Morshedi, D.; Doostkam, M.; Yaghmaei, S.; Aliakbari, F.; Singh, G.; Arpanaei, A. The effect of mesoporous silica nanoparticle surface chemistry and concentration on the $\alpha$-synuclein fibrillation. RSC Adv. 2015, 5, 60966-60974. [CrossRef]

105. Mohammadi, S.; Nikkhah, M.; Hosseinkhani, S. Investigation of the effects of carbon-based nanomaterials on A53T alpha-synuclein aggregation using a whole-cell recombinant biosensor. Int. J. Nanomed. 2017, 12, 8831-8840. [CrossRef] [PubMed]

106. Sun, Y.; Kakinen, A.; Zhang, C.; Yang, Y.; Faridi, A.; Davis, T.P.; Cao, W.; Ke, P.C.; Ding, F. Amphiphilic surface chemistry of fullerenols is necessary for inhibiting the amyloid aggregation of alpha-synuclein NACore. Nanoscale 2019, 11, 11933-11945. [CrossRef] [PubMed]

107. Milowska, K.; Grochowina, J.; Katir, N.; El Kadib, A.; Majoral, J.-P.; Bryszewska, M.; Gabryelak, T. Viologen-Phosphorus Dendrimers Inhibit $\alpha$-Synuclein Fibrillation. Mol. Pharm. 2013, 10, 1131-1137. [CrossRef] [PubMed]

108. Milowska, K.; Malachowska, M.; Gabryelak, T. PAMAM G4 dendrimers affect the aggregation of $\alpha$-synuclein. Int. J. Biol. Macromol. 2011, 48, 742-746. [CrossRef]

109. Rekas, A.; Lo, V.; Gadd, G.E.; Cappai, R.; Yun, S.I. PAMAM Dendrimers as Potential Agents against Fibrillation of $\alpha$-Synuclein, a Parkinson's Disease-Related Protein. Macromol. Biosci. 2009, 9, 230-238. [CrossRef]

110. Milowska, K.; Gabryelak, T.; Bryszewska, M.; Caminade, A.-M.; Majoral, J.-P. Phosphorus-containing dendrimers against $\alpha$-synuclein fibril formation. Int. J. Biol. Macromol. 2012, 50, 1138-1143. [CrossRef]

111. Milowska, K.; Szwed, A.; Mutrynowska, M.; Gomez-Ramirez, R.; de la Mata, F.J.; Gabryelak, T.; Bryszewska, M. Carbosilane dendrimers inhibit $\alpha$-synuclein fibrillation and prevent cells from rotenone-induced damage. Int. J. Pharm. 2015, 484, 268-275. [CrossRef] [PubMed]

112. Mohammad-Beigi, H.; Morshedi, D.; Shojaosadati, S.A.; Pedersen, J.N.; Marvian, A.T.; Aliakbari, F.; Christiansen, G.; Pedersen, J.S.; Otzen, D.E. Gallic acid loaded onto polyethylenimine-coated human serum albumin nanoparticles (PEI-HSA-GA NPs) stabilizes $\alpha$-synuclein in the unfolded conformation and inhibits aggregation. RSC Adv. 2016, 6, 85312-85323. [CrossRef]

113. Aliakbari, F.; Mohammad-Beigi, H.; Rezaei-Ghaleh, N.; Becker, S.; Dehghani Esmatabad, F.; Eslampanah Seyedi, H.A.; Bardania, H.; Tayaranian Marvian, A.; Collingwood, J.F.; Christiansen, G.; et al. The potential of zwitterionic nanoliposomes against neurotoxic alpha-synuclein aggregates in Parkinson's Disease. Nanoscale 2018, 10, 9174-9185. [CrossRef] [PubMed]

114. Zhu, M.; Li, J.; Fink, A.L. The Association of $\alpha$-Synuclein with Membranes Affects Bilayer Structure, Stability and Fibril Formation. J. Biol. Chem. 2003, 278, 40186-40197. [CrossRef] [PubMed]

115. Zhu, M.; Fink, A.L. Lipid Binding Inhibits $\alpha$-Synuclein Fibril Formation. J. Biol. Chem. 2003, 278, $16873-16877$. [CrossRef] [PubMed]

116. Yushchenko, D.A.; Fauerbach, J.A.; Thirunavukkuarasu, S.; Jares-Erijman, E.A.; Jovin, T.M. Fluorescent Ratiometric MFC Probe Sensitive to Early Stages of $\alpha$-Synuclein Aggregation. J. Am. Chem. Soc. 2010, 132, 7860-7861. [CrossRef] [PubMed]

117. Meisl, G.; Kirkegaard, J.B.; Arosio, P.; Michaels, T.C.T.; Vendruscolo, M.; Dobson, C.M.; Linse, S.; Knowles, T.P.J. Molecular mechanisms of protein aggregation from global fitting of kinetic models. Nat. Protoc. 2016, 11, 252-272. [CrossRef]

118. Brancolini, G.; Corazza, A.; Vuano, M.; Fogolari, F.; Mimmi, M.C.; Bellotti, V.; Stoppini, M.; Corni, S.; Esposito, G. Probing the Influence of Citrate-Capped Gold Nanoparticles on an Amyloidogenic Protein. ACS Nano 2015, 9, 2600-2613. [CrossRef] 
119. Zhou, W.; Long, C.; Reaney, S.H.; Di Monte, D.A.; Fink, A.L.; Uversky, V.N. Methionine oxidation stabilizes non-toxic oligomers of $\alpha$-synuclein through strengthening the auto-inhibitory intra-molecular long-range interactions. Biochim. Biophys. Acta Mol. Basis Dis. 2010, 1802, 322-330. [CrossRef]

120. Van Meer, G.; Voelker, D.R.; Feigenson, G.W. Membrane lipids: Where they are and how they behave. Nat. Rev. Mol. Cell Biol. 2008, 9, 112-124. [CrossRef]

121. Vanni, S.; Hirose, H.; Barelli, H.; Antonny, B.; Gautier, R. A sub-nanometre view of how membrane curvature and composition modulate lipid packing and protein recruitment. Nat. Commun. 2014, 5, 4916. [CrossRef] [PubMed]

122. Kjaer, L.; Giehm, L.; Heimburg, T.; Otzen, D. The Influence of Vesicle Size and Composition on $\alpha$-Synuclein Structure and Stability. Biophys. J. 2009, 96, 2857-2870. [CrossRef]

123. Galvagnion, C.; Brown, J.W.P.; Ouberai, M.M.; Flagmeier, P.; Vendruscolo, M.; Buell, A.K.; Sparr, E.; Dobson, C.M. Chemical properties of lipids strongly affect the kinetics of the membrane-induced aggregation of $\alpha$-synuclein. Proc. Natl. Acad. Sci. USA 2016, 113, 7065-7070. [CrossRef] [PubMed]

124. Fink, A.L. The Aggregation and Fibrillation of $\alpha$-Synuclein. Acc. Chem. Res. 2006, 39, 628-634. [CrossRef] [PubMed]

125. Giehm, L.; Svergun, D.I.; Otzen, D.E.; Vestergaard, B. Low-resolution structure of a vesicle disrupting $\alpha$-synuclein oligomer that accumulates during fibrillation. Proc. Natl. Acad. Sci. USA 2011, 108, 3246-3251. [CrossRef]

126. Hellstrand, E.; Nowacka, A.; Topgaard, D.; Linse, S.; Sparr, E. Membrane Lipid Co-Aggregation with $\alpha$-Synuclein Fibrils. PLoS ONE 2013, 8, e77235. [CrossRef]

127. Barracchia, C.G.; Tira, R.; Parolini, F.; Munari, F.; Bubacco, L.; Spyroulias, G.A.; D’Onofrio, M.; Assfalg, M. Unsaturated Fatty Acid-Induced Conformational Transitions and Aggregation of the Repeat Domain of Tau. Molecules 2020, 25, 2716. [CrossRef]

128. Sparr, E.; Linse, S. Lipid-protein interactions in amyloid formation. Biochim. Biophys. Acta Proteins Proteom. 2019, 1867, 455-457. [CrossRef]

129. Auluck, P.K.; Caraveo, G.; Lindquist, S. $\alpha$-Synuclein: Membrane Interactions and Toxicity in Parkinson's Disease. Annu. Rev. Cell Dev. Biol. 2010, 26, 211-233. [CrossRef]

130. Nemani, V.M.; Lu, W.; Berge, V.; Nakamura, K.; Onoa, B.; Lee, M.K.; Chaudhry, F.A.; Nicoll, R.A.; Edwards, R.H. Increased Expression of $\alpha$-Synuclein Reduces Neurotransmitter Release by Inhibiting Synaptic Vesicle Reclustering after Endocytosis. Neuron 2010, 65, 66-79. [CrossRef]

131. Rovere, M.; Sanderson, J.B.; Fonseca-Ornelas, L.; Patel, D.S.; Bartels, T. Refolding of helical soluble $\alpha$-synuclein through transient interaction with lipid interfaces. FEBS Lett. 2018, 592, 1464-1472. [CrossRef] [PubMed]

132. Cohen, F.E.; Kelly, J.W. Therapeutic approaches to protein-misfolding diseases. Nature 2003, 426, $905-909$. [CrossRef] [PubMed]

133. Haass, C.; Selkoe, D.J. Soluble protein oligomers in neurodegeneration: Lessons from the Alzheimer's amyloid $\beta$-peptide. Nat. Rev. Mol. Cell Biol. 2007, 8, 101-112. [CrossRef] [PubMed]

134. Cendrowska, U.; Silva, P.J.; Ait-Bouziad, N.; Müller, M.; Guven, Z.P.; Vieweg, S.; Chiki, A.; Radamaker, L.; Kumar, S.T.; Fändrich, M.; et al. Unraveling the complexity of amyloid polymorphism using gold nanoparticles and cryo-EM. Proc. Natl. Acad. Sci. USA 2020, 117, 6866-6874. [CrossRef] [PubMed]

135. Heegaard, P.M.H.; Boas, U.; Otzen, D.E. Dendrimer Effects on Peptide and Protein Fibrillation. Macromol. Biosci. 2007, 7, 1047-1059. [CrossRef] [PubMed]

136. Laumann, K.; Boas, U.; Larsen, H.M.; Heegaard, P.M.H.; Bergström, A.-L. Urea and Thiourea Modified Polypropyleneimine Dendrimers Clear Intracellular $\alpha$-Synuclein Aggregates in a Human Cell Line. Biomacromolecules 2015, 16, 116-124. [CrossRef]

137. Holubová, M.; Štěpánek, P.; Hrubý, M. Polymer materials as promoters/inhibitors of amyloid fibril formation. Colloid Polym. Sci. 2020. [CrossRef]

138. Lee, D.; Choe, Y.-J.; Lee, M.; Jeong, D.H.; Paik, S.R. Protein-Based SERS Technology Monitoring the Chemical Reactivity on an $\alpha$-Synuclein-Mediated Two-Dimensional Array of Gold Nanoparticles. Langmuir 2011, 27, 12782-12787. [CrossRef]

139. Kim, C.-H.; Bhak, G.; Lee, J.; Sung, S.; Park, S.; Paik, S.R.; Yoon, M.-H. Controlled Charge Trapping and Retention in Large-Area Monodisperse Protein Metal-Nanoparticle Conjugates. ACS Appl. Mater. Interfaces 2016, 8, 11898-11903. [CrossRef] 
140. Lee, D.; Hong, J.W.; Park, C.; Lee, H.; Lee, J.E.; Hyeon, T.; Paik, S.R. Ca ${ }^{2+}$-Dependent Intracellular Drug Delivery System Developed with "Raspberry-Type" Particles-on-a-Particle Comprising Mesoporous Silica Core and $\alpha$-Synuclein-Coated Gold Nanoparticles. ACS Nano 2014, 8, 8887-8895. [CrossRef]

141. Lee, D.; Choe, Y.-J.; Choi, Y.S.; Bhak, G.; Lee, J.; Paik, S.R. Photoconductivity of Pea-Pod-Type Chains of Gold Nanoparticles Encapsulated within Dielectric Amyloid Protein Nanofibrils of $\alpha$-Synuclein. Angew. Chem. Int. Ed. 2011, 50, 1332-1337. [CrossRef] [PubMed]

142. Colby, R.; Hulleman, J.; Padalkar, S.; Rochet, J.C.; Stanciu, L.A. Biotemplated synthesis of metallic nanoparticle chains on an alpha-synuclein fiber scaffold. J. Nanosci. Nanotechnol. 2008, 8, 973-978. [CrossRef] [PubMed]

143. Kumar, J.; Eraña, H.; López-Martínez, E.; Claes, N.; Martín, V.F.; Solís, D.M.; Bals, S.; Cortajarena, A.L.; Castilla, J.; Liz-Marzán, L.M. Detection of amyloid fibrils in Parkinson's disease using plasmonic chirality. Proc. Natl. Acad. Sci. USA 2018, 115, 3225-3230. [CrossRef] [PubMed]

Publisher's Note: MDPI stays neutral with regard to jurisdictional claims in published maps and institutional affiliations.

(C) 2020 by the authors. Licensee MDPI, Basel, Switzerland. This article is an open access article distributed under the terms and conditions of the Creative Commons Attribution (CC BY) license (http://creativecommons.org/licenses/by/4.0/). 